\title{
Hybrid Wiener model: an on-board approach using post-flight data for gas turbine aero-engines modelling
}

\author{
Zhiyuan Wei ${ }^{a}$, Soheil Jafari ${ }^{b}$, Shuguang Zhang ${ }^{a *}$, Theoklis Nikolaidis ${ }^{b}$ \\ a. School of Transportation Science and Engineering, Beihang University, Beijing 100191, China \\ b. Centre for Propulsion Engineering, School of Aerospace Transport and Manufacturing, Cranfield University, \\ Bedfordshire MK43 OAL, UK \\ * Corresponding author. \\ Email: gnahz@buaa.edu.cn (S. Zhang)
}

\section{Highlights}

- An on-board model using post-flight data for gas turbine aero-engines is proposed.

- Unmeasured thrust, surge margin, and turbine entry temperature are estimated.

- Engine health status and steady-state operating lines are updated periodically.

- Both steady and transient modelling accuracy are guaranteed for degraded engines.

\section{Abstract}

On-board modelling of gas turbine aero-engines over the life cycle is a promising solution for engine performance improvement and future aero-propulsion requirements. In this paper, an on-board modelling approach named Hybrid Wiener model (HWM) is proposed for gas turbine aero-engines using post-flight engine monitoring data, which aims at estimating the unmeasured safety-critical control parameters (i.e. thrust, surge margin, and turbine entry temperature) by monitoring the engine degradation effects. Common on-board models for nominal engines, i.e. piecewise linear model, novel generalized describing function, and Wiener model, are systematically tested on a validated turbofan 
engine aero-thermal model. Simulations demonstrate that Wiener model is the best candidate for nominal engines. HWM is therefore constructed with the integration of on-line Wiener models and an off-line adaptation approach. The on-line part computes the unmeasured safety-critical parameters in a real-time manner. Meanwhile, the off-line adaptation part serves to periodically update the nonlinear static blocks of on-line Wiener models using the post-flight data in order to match the particular degraded engine. Idle to full-power rapid transient simulations of HWM are carried on the turbofan engine aero-thermal model for degradation simulations using publicly available data. Results from the studied turbofan engine at different flight cycles demonstrate that HWM is not only able to guarantee the steady accuracy for thrust, surge margin, and turbine entry temperature, but also ensures that the maximum transient errors for these safety-critical parameters are less than $4.66 \%$ during rapid acceleration states. Moreover, the percent errors of peak values for surge margin and turbine entry temperature between HWM and the engine are within $0.50 \%$. The performance of the proposed HWM over the engine life cycle is therefore confirmed.

\section{Key words}

Hybrid Wiener model, Gas turbine aero-engines, On-board modelling, Post-flight data, Degradation

\section{Nomenclature}

BST booster 


\begin{tabular}{|c|c|}
\hline EPR & engine pressure ratio \\
\hline $\mathrm{F}$ & thrust \\
\hline FAR & fuel-to-air ratio \\
\hline $\mathrm{FC}$ & flight cycle \\
\hline HPC & high-pressure compressor \\
\hline HPT & high-pressure turbine \\
\hline HWM & Hybrid Wiener model \\
\hline ISA & international standard atmosphere \\
\hline $\mathrm{J}$ & objective function \\
\hline LPT & low-pressure turbine \\
\hline NGDF & novel generalized describing function \\
\hline P3 & high-pressure compressor outlet pressure \\
\hline PWL & piecewise linear \\
\hline SLS & sea-level static \\
\hline SM & surge margin \\
\hline SS Op-Line & steady-state operating lines \\
\hline $\mathrm{T} 4$ & turbine entry temperature \\
\hline Wf & fuel flow \\
\hline$u$ & control input \\
\hline$\hat{h}$ & health parameters estimation \\
\hline$y$ & measurements \\
\hline
\end{tabular}


estimated measurements

$\tau$

time constant

$\Gamma$

flow capacity

$\eta \quad$ isentropic efficiency

$\pi$

pressure ratio

$\Delta$

delta

subscript

acc

acceleration

est

estimated

\section{Introduction}

The physical causes behind gas turbine aero-engines degradation over the life cycle inevitably lower the safety margin $[1,2]$ and overall efficiency $[3,4]$ of the engine. These mechanisms include blade surface changes (due to erosion, corrosion, or fouling) that influence blade aerodynamics [5, 6] and tip clearance increases that affect parasitic flows [7]. Degradation effects with the increasing flight cycles gradually deteriorate the gas path component health status, which is still difficult to accurately obtain $[8,9]$. As a consequence, a significantly conservative safety margin that is usually set to endof-life engines must be considered under the existing industrial engine control system using sensorbased strategies [10-12]. Moreover, the next generation of aero-propulsion systems (e.g. Ultra High 
Bypass Ratio (UHBR) engines and Hybrid Electric Propulsion (HEP)) should be designed to deal with challenging targets of ultra-high efficiency and ultra-low emissions [13-15]. These ambitious targets could not be achieved only by means of marginal improvement in the engine component design and development. Control-oriented on-board modelling of gas turbine aero-engines is a promising solution for the engine performance improvement, model-based controllers design as well as future aeropropulsion requirements [16]. Therefore, this promising solution is of great importance in the conservatism reduction and the efficiency enhancement in gas turbine engines.

On-board modelling of gas turbine aero-engines for control purpose is firstly investigated on nominal engines, which represent new or ideal engine performance. Piecewise linear model that links a family of state-space models and engine steady points is widely utilized to predict the engine transient performance $[17,18]$. Chiras et al. examined the nonlinear global identification modelling, including nonlinear autoregressive network with exogenous input and neural network, based on a set of turbofan engine experiment data [19-21]. The dynamic relationship between fuel flow and engine spool speed was successfully established in a large operating region of the engine. In 2006, Lichtsinder and Levy proposed novel generalized describing function (NGDF) to obtain a high-fidelity on-board model, especially under rapid fuel flow variations [22]. The accuracy of NGDF is guaranteed through an error minimization optimization approach. Wiener model, as one of the block structure models containing cascade connections of linear dynamic blocks and nonlinear static blocks for nonlinear system modelling, is also employed in gas turbine engines on-board modelling due to its low computational burden and dynamic characteristics [23]. However, due to the normal aging in gas turbine aero-engines with the increasing flight cycles, the engine performance deviates from its nominal state. Hence, 
nominal engines on-board model could not deliver desired fidelity for a monitored degraded engine anymore.

Degraded engines on-board modelling are therefore motivated, especially because the unmeasured safety-critical parameters, thrust, surge margin, and turbine entry temperature, are tightly coupled with the engine health status [12]. Luppold et al. initially invented a self-tuning on-board real-time model (STORM) for turbofan engines on-board modelling with degradation effects [24]. Kalman filter was applied to estimate engine health parameters that are aimed to tune the piecewise linear model to match the degraded engine. Sugiyama then proposed constant gain extended Kalman filter (CGEKF) for gas turbine engines on-board modelling while avoid the extensive computational burden from extended Kalman filter [25]. Lietzau and Kreiner from the MTU aero engine developed an on-board turbofan engine model using a Kalman filter as an observer [26]. Surge margin and turbine entry temperature estimation were directly feedback to the control system via the assessment of efficiency in gas path components. However, these on-board models only focus on limited gas path components. The gradual degradation in gas turbine engines inevitably influences the performance of all the major gas path components [27, 28]. Kobayashi et al. developed hybrid Kalman filter (HKF), for gas turbine engines under gradual degradation [29, 30]. An off-line trending system was incorporated to update health baseline for on-board modelling accuracy enhancement. In 2008, Litt et al. presented a singular value decomposition (SVD) approach for large turbofans on-board modelling, which was aimed at decreasing the surge margin estimation error [31]. Simon et al. proposed a more systematic on-board modelling approach, optimal tuner Kalman filter (OTKF), for civil turbofans to decrease the mean square estimation error from SVD approach [18, 32, 33]. In 2016, Csank and Collony further extended 
OTKF to OTEKF (Optimal Tuner Extended Kalman Filter) to improve the estimation accuracy for unmeasured control parameters during rapid transients [34]. However, even regarding the most recent advancement in on-board modelling technique for degraded engines, OTKF and OTEKF, there is still a noticeable relative estimation error for surge margin, up to $20 \%$, in rapid acceleration state for middle-aged and end-of-life engines. This significant estimation error may be subject to their fixed baseline setting, which is designed on the health status of middle-aged engines.

In this paper, an on-board modelling approach using post-flight data named Hybrid Wiener model (HWM) is proposed for gas turbine aero-engines over the life cycle. The proposed model aims at estimating unmeasured safety-critical control parameters (i.e. thrust, surge margin and turbine entry temperature) during rapid transient states. HWM extends Wiener model with an off-line adaptation approach to monitor the engine health status. Hence, the proposed HWM is periodically updated to match the particular degraded engine.

The remainder of this paper is organized as follows. In section two, a turbofan engine aero-thermal model for nominal conditions is developed and validated against experimental results. Degradation simulations of the turbofan engine aero-thermal model are extended using publicly available data to act as a baseline for on-board modelling verification. Next, in section three, common on-board modelling approaches for nominal engines are briefly described and systematically tested on the validated turbofan engines aero-thermal model to identify the best candidate model. The modelling details of HWM are comprehensively presented in section four. Simulations are carried on the turbofan engine aero-thermal model with degradation effects to confirm the effectiveness of HWM during rapid transient states over the engine life cycle. 


\section{Gas turbine engines aero-thermal model with degradation effects}

Gas turbine engines aero-thermal model with degradation effects could be served as a baseline for the validation of the on-board model. In this section, an aero-thermal model of a turbofan engine under nominal condition is developed and validated against experiment results as the first step. Then, the nominal turbofan engine aero-thermal model is extended for degradation simulations using publicly available degradation data.

The examined engine is a dual-spool, separate exhaust, fixed geometry turbofan engine with an intended application to general aircraft. Major components in this engine are fan, high-pressure compressor (HPC), combustion chamber, high-pressure turbine (HPT), low-pressure turbine (LPT), bypass nozzle, and core nozzle. The only control variable of this engine is fuel flow (Wf). The schematic and the take-off specification of the engine at sea-level static (SLS) and international standard atmosphere (ISA) are shown in Fig. 1and Table 1, respectively.

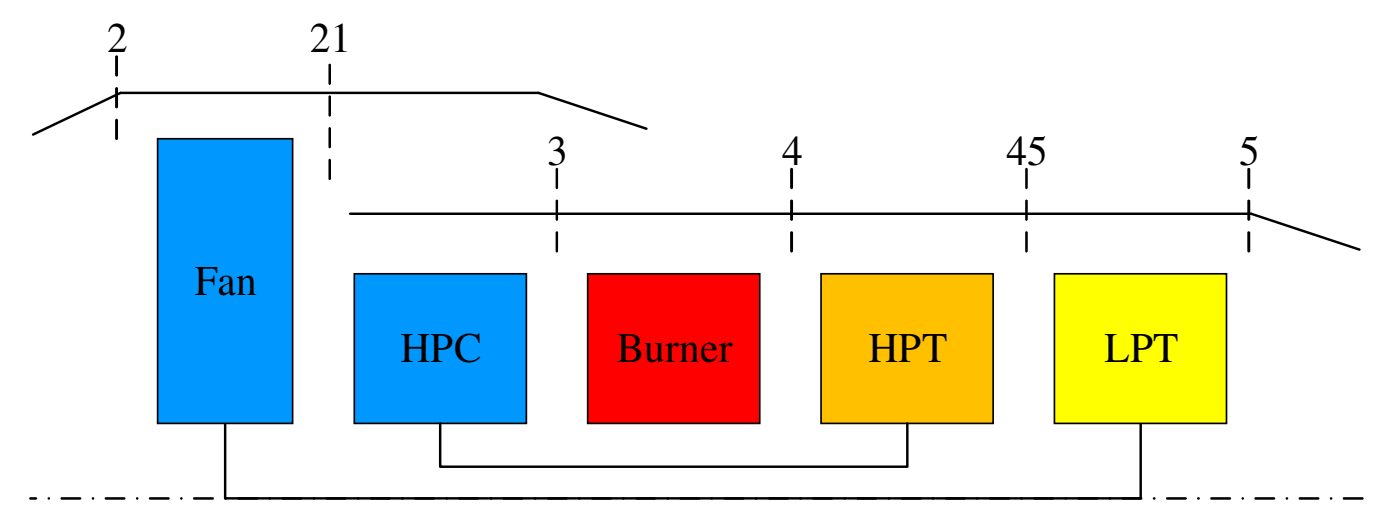

Fig. 1 Schematic of the examined dual-spool turbofan engine

Table 1 Take-off specification of the examined dual-spool turbofan engine 


\begin{tabular}{lc}
\hline Parameters & Values \\
\hline Ambient temperature (K) & 288.15 \\
Ambient pressure $(\mathrm{kPa})$ & 101.325 \\
Intake mass flow (kg/s) & 13.68 \\
Low-pressure spool speed (rpm) & 44233 \\
High-pressure spool speed (rpm) & 50990 \\
Fan pressure ratio & 1.20 \\
High-pressure compressor pressure ratio & 4.38 \\
Turbine entry temperature (K) & 1108 \\
Fuel flow (kg/s) & 0.036 \\
Maximal thrust $(\mathrm{kg})$ & 246.48 \\
\hline
\end{tabular}

An aero-thermal model of the examined turbofan engine is firstly developed to represent the engine steady-state and transient performance under nominal conditions (i.e. clean or ideal engine performance). This aero-thermal engine model is a physics-based model that is constructed by the component characteristic maps to guarantee the continuity of flow capacity and work balance. Modelling details could be referred to $[35,36]$. The simulated steady-state operating line of the aerothermal model on HPC map at the sea-level static condition matches well with that of the experimental result from the engine manufacturer, as illustrated in Fig. 2. This result supports the utilization of the aero-thermal model for the extension of degradation simulations. 


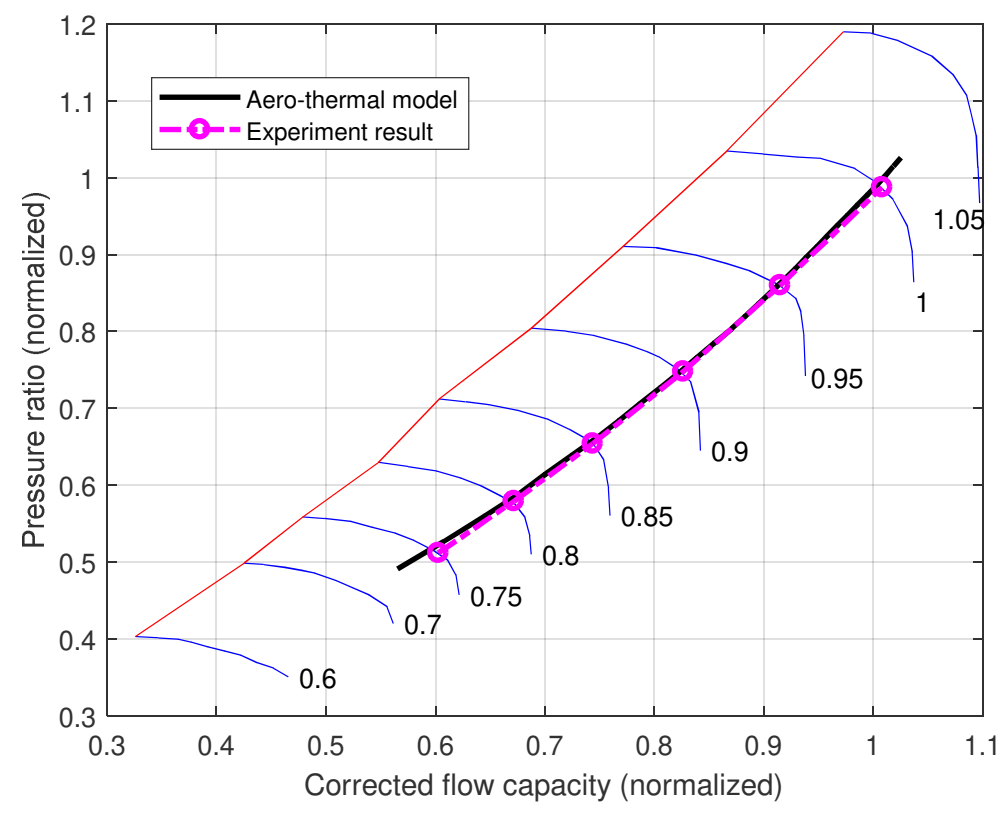

Fig. 2 Validation of the steady-state operating line on HPC map between the aero-thermal model and experiment result

The next step is how to realistically model the degradation effects in the aero-thermal engine model. Degradation on gas turbine engines performance is usually modelled by introducing health parameters for compressors and turbines, which represent the health status/deviation of major components in the gas path $[1,37]$. Therefore, degraded component maps could be obtained via the movement of their original clean maps based on these health parameters. This is based on the assumption that the shape of degraded component maps remains almost the same as their original maps since component geometries do not hugely change due to the degradation effects [38]. The health parameters are defined in Eqs. (1)-(2) for compressors (e.g. fan, booster, and HPC) and turbines (e.g. HPT and LPT),

$$
\begin{gathered}
\Delta \Gamma=\frac{\Gamma_{\text {real }}-\Gamma_{\text {clean }}}{\Gamma_{\text {clean }}}=\frac{\Gamma_{\text {real }}}{\Gamma_{\text {clean }}}-1 \\
\Delta \eta=\eta_{\text {real }}-\eta_{\text {clean }}
\end{gathered}
$$


where $\Gamma_{\text {real }}$ and $\Gamma_{\text {clean }}$ are corrected flow capacity for degraded maps and clean maps of compressors or turbines, respectively; $\eta_{\text {real }}$ and $\eta_{\text {clean }}$ denote isentropic efficiency for degraded maps and clean maps of compressors or turbines; $\Delta \Gamma$ and $\Delta \eta$ are the health parameters for flow capacity and isentropic efficiency, respectively.

Particularly, for a realistic representation of the degradation effects for the compressors including fan, booster and high-pressure compressor, a third health parameters, for pressure ratio $\Delta \pi_{C}$ should be introduced, as defined in Eq. (3), in combination with the health parameters for flow capacity and isentropic efficiency in Eqs. (1)-(2) [39, 40].

$$
\Delta \pi_{\mathrm{C}}=\frac{\pi_{\mathrm{C}, \text { real }}-\pi_{\mathrm{C}, \text { clean }}}{\pi_{\mathrm{C}, \text { clean }}}=\frac{\pi_{\mathrm{C}, \text { real }}}{\pi_{\mathrm{C}, \text { clean }}}-1
$$

In Eq. (3), $\pi_{\mathrm{C} \text {,real }}$ and $\pi_{\mathrm{C} \text {,clean }}$ are pressure ratio for degraded compressor maps and clean compressor map, respectively. The approach for degraded compressor map generation defined in Eqs. (1)-(3) was also confirmed by the experiment on a deteriorated V2500 turbofan engine [41]. The health parameter for pressure ratio $\Delta \pi_{C}$ of compressor is usually assumed to be equal to that of flow capacity $\Delta \Gamma_{C}$ since they have the same effects on engine performance, and this avoids multiple solutions in health parameter estimation, as shown in Eq. (4) [38]. This assumption is also utilized in PYTHIA, an in-house gas turbine diagnosis software developed at Cranfield University which has been tested on gas turbines field data [42].

$$
\Delta \pi_{C}=\Delta \Gamma_{C}
$$

In order to extend the validated turbofan aero-thermal model under nominal conditions for degradation simulations, the gas path components degradation data quantified by the National 
Aeronautics and Space Administration (NASA) based on in-service data from airliners, airframe manufacturers, and engine test results from JT9D turbofan engines, is utilized here, as shown in Table $2[27,43,44]$. It should be noted that only the health parameters of flow capacity for HPT and LPT are positive due to the expanded turbine throat area resulted from degradation effects. All the other health parameters remain negative with the increasing flight cycles.

Table 2 Degradation data of turbofan engines quantified by NASA [27, 43, 44]

\begin{tabular}{ccccccccccc}
\hline $\begin{array}{c}\text { Flight } \\
\text { cycle }\end{array}$ & $\Delta \eta_{\text {Fan }}$ & $\Delta \Gamma_{\text {Fan }}$ & $\Delta \eta_{B S T}$ & $\Delta \Gamma_{B S T}$ & $\Delta \eta_{H P C}$ & $\Delta \Gamma_{H P C}$ & $\Delta \eta_{H P T}$ & $\Delta \Gamma_{H P T}$ & $\Delta \eta_{L P T}$ & $\Delta \Gamma_{L P T}$ \\
& $(\%)$ & $(\%)$ & $(\%)$ & $(\%)$ & $(\%)$ & $(\%)$ & $(\%)$ & $(\%)$ & $(\%)$ & $(\%)$ \\
\hline 0 & 0 & 0 & 0 & 0 & 0 & 0 & 0 & 0 & 0 & 0 \\
3000 & -1.50 & -2.04 & -1.46 & -2.08 & -2.94 & -3.91 & -2.63 & +1.76 & -0.54 & +0.25 \\
6000 & -2.85 & -3.65 & -2.61 & -4.00 & -9.40 & -14.06 & -3.81 & +2.57 & -1.08 & +0.42 \\
\hline
\end{tabular}

Therefore, the turbofan engine aero-thermal model for degradation simulations is achieved using degraded component characteristic maps that are generated by Eqs. (1)-(4) and the degradation data in Table 2. The health parameters in Table 2 were applied to the corresponding components in the examined dual-spool turbofan engine, as shown in Fig. 1. Actually, the health parameters for flow capacity and pressure ratio act as a scaling factor for the clean maps, while the health parameters for isentropic efficiency serve as an adder for the clean maps.

Overall, the validated aero-thermal model for nominal conditions and its extended counterpart for degradation simulations are used as baseline models for on-board modelling verification in the rest of the paper. 


\section{On-board modelling approaches for nominal engines}

Up to now, several efforts have been spared on the on-board modelling for nominal gas turbine aero-engines. The term, nominal engine modelling, here aims to describe the ideal/clean engine performance without account for the un-deterministic engine-to-engine variation from gradual degradation effects through the engine life cycle [45]. The most common on-board models for nominal engines are piecewise linear (PWL) model $[17,18]$, novel generalized describing function (NGDF) model [22] and Wiener model [23]. As was mentioned earlier, this paper endeavors to propose a hybrid on-board modelling approach for degraded engines. Therefore, in this section, the most common onboard models for nominal engines are briefly described and systematically tested on a dual-spool turbofan engine in order to identify the best candidate nominal engine's on-board model.

\subsection{Piecewise linear model}

Piecewise linear (PWL) model is an extensively-used on-board model for nominal aero gas turbine engines $[17,18]$. It contains a set of steady state points and the corresponding linear state space models along the engine steady operating line. Thus the engine transient response could be predicted via the interpolation between the steady points and the linear state space models by means of a scheduling parameter, like engine spool speed. The state-space model is a linearized representation around an engine trim point, as shown in Eq. (5),

$$
\begin{aligned}
& \dot{x}=A\left(x-x_{\text {trim }}\right)+B\left(u-u_{\text {trim }}\right) \\
& y-y_{\text {trim }}=C\left(x-x_{\text {trim }}\right)+D\left(u-u_{\text {trim }}\right)
\end{aligned}
$$

where $x, y, u$ are state parameters, output parameters and control variables, respectively; the subscript 
trim denotes the engine trim point; $A, B, C, D$ are system matrix in corresponding dimensions. Parameters of the system matrix are obtained by partial derivative method [18].

The main computation procedure of PWL model is summarized in Table $3[17,18]$. The input of PWL model is state-space model, static points, scheduling parameters, control input and other simulation settings. At each time step, the current steady base point and state-space model is searched by the scheduling parameter. Then the engine dynamic response at each time step is predicted as a sum of the current steady base point and the incremental of the output variable from state space model.

Table 3 PWL on-board modelling algorithm adapted from [17, 18]

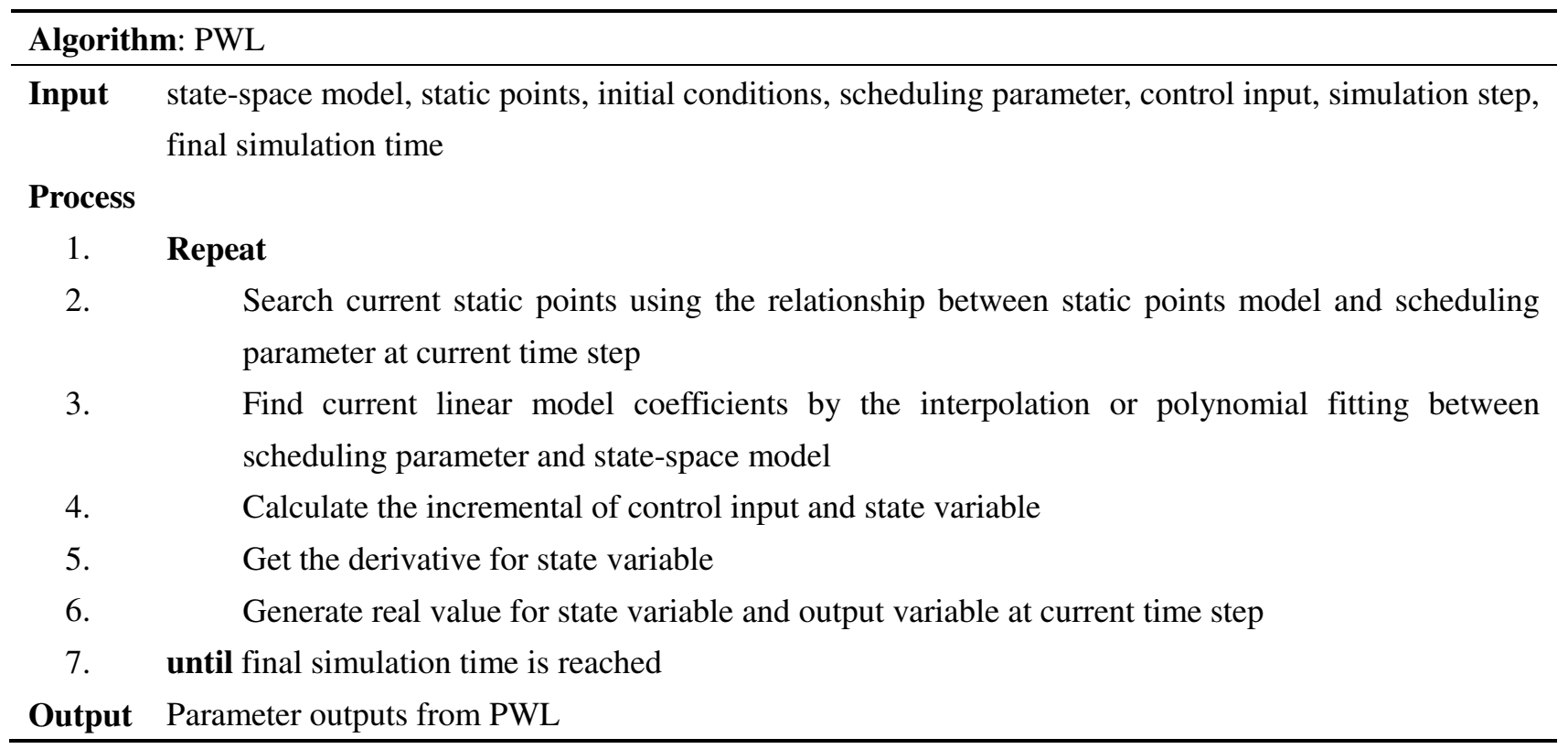

\subsection{Novel generalized describing function}

NGDF proposed by Lichtsinder and Levy is another on-board modelling technique for nominal engines [22]. The main philosophy behind NGDF is to obtain a high-fidelity on-board model, 
especially under large and rapid fuel flow variation. This is based on the fact that the significant fuel flow change is highly concerned in the engine control system because the engine runs closer to the safety limits (e.g. surge limit, over-temperature limit and blown-out limit) during rapid transient states. The accuracy of NGDF is guaranteed through an incremental approach, as shown in Fig. 3.

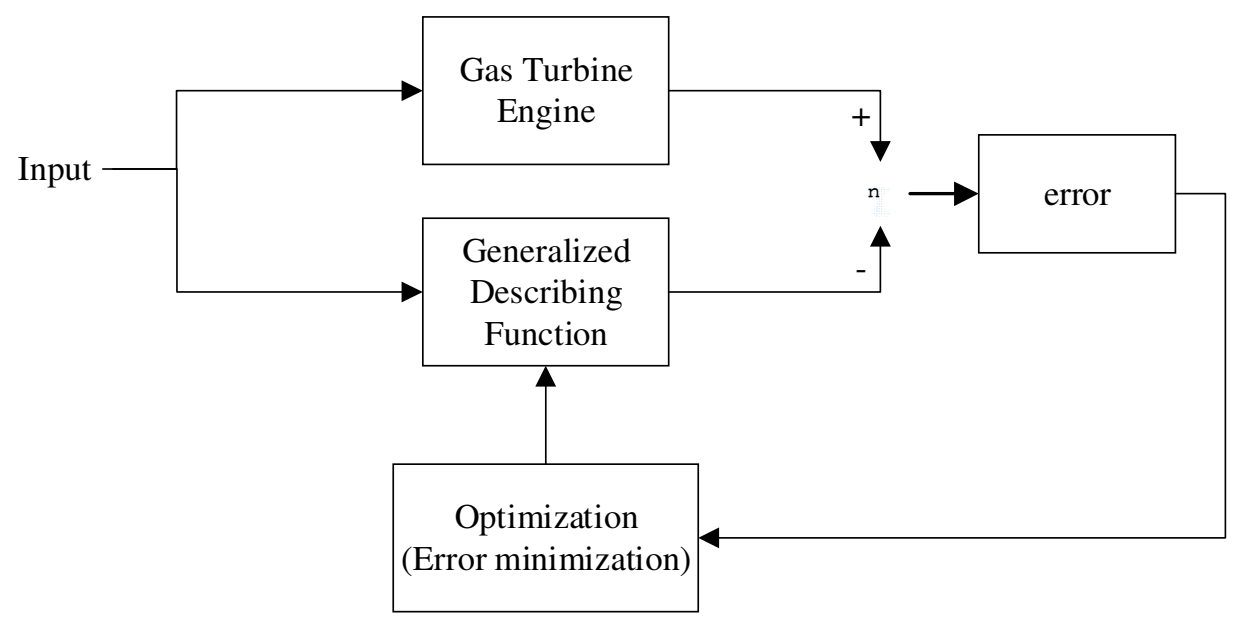

Fig. 3 NGDF schematic for nominal engine on-board modelling adapted from [22]

The generalized describing function in NGDF is in a lead-lag form, as shown in Eq. (6),

$$
W(s)=K(H, M a) \frac{\tau_{1}(H, M a) s+1}{\tau_{2}(H, M a) s+1}
$$

where the parameters $K, \tau_{1}$ and $\tau_{1}$ all depend on height $(H)$ and Mach number $(M a)$; $s$ denotes the complex variable. Therefore, the very simple structure and incremental approach in NGDF enables it the capability for on-board application over the whole flight envelope.

\subsection{Wiener model}

Wiener model is one of the block structure models with extensive application in nonlinear system modelling [46]. Block structure models comprise Hammerstein model, Wiener model, Wiener- 
Hammerstein model and Hammerstein-Wiener model, as shown in Fig. 4 [23]. These models contain different cascade connections of linear dynamic elements and nonlinear static elements to represent the nonlinear behavior of the modelling system. Hammerstein model is usually regarded as a candidate for systems under which nonlinearity is only affected by the direct current gain [17]. The input amplitude does not influence the dynamic behavior of the model. Thus it seems this model is not appropriate for gas turbine engine modelling since the engine dynamics vary significantly with different input amplitudes. Conversely, Wiener model represents the nonlinearities for different input amplitudes [17, 47]. These dynamics in Wiener model is consistent with the dynamic characteristics of gas turbine engines whose gains and response time vary with input magnitude and operating points [48]. Wiener-Hammerstein model and Hammerstein-Wiener model have a relatively complex structure and a large number of parameters so that these models are difficult to generate [23]. Therefore, in block structure models, Wiener model seems to be the superior choice for engine on-board modelling due to its dynamics and low computational burden.

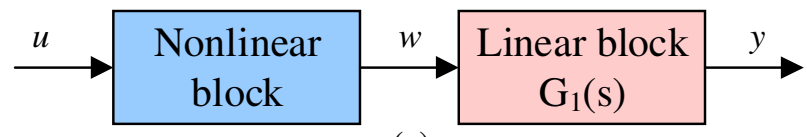

(a)

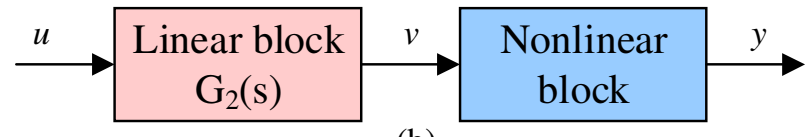

(b)

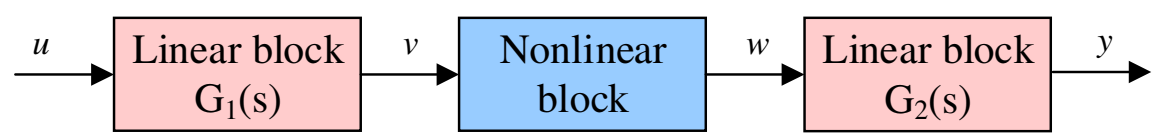

(c)

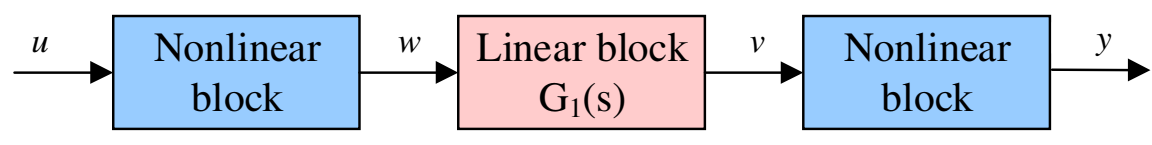

(d)

Fig. 4 Block structure model (a)Hammerstein, (b) Wiener, (c) Wiener-Hammerstein, (d) Hammerstein-Wiener adapted 
The first step in producing Wiener model for gas turbine engines on-board modelling is the selection of input signals. As was mentioned earlier, the unmeasured parameters, thrust, turbine entry temperature (T4) and surge margin (SM), are highly concerned in this study. The fuel flow (Wf) is selected as the input for thrust. Some previous studies demonstrate that fuel-to-air ratio (FAR) is directly related to turbine entry temperature and surge margin [11]. Under this motivation, the measurable input signal, fuel flow divided by high-pressure compressor outlet pressure (Wf/P3), which has a strong relationship with unmeasured FAR, is selected as the input for T4 and SM in this study. The configuration of Wiener model for nominal engines on-board modelling is illustrated in Fig. 5.

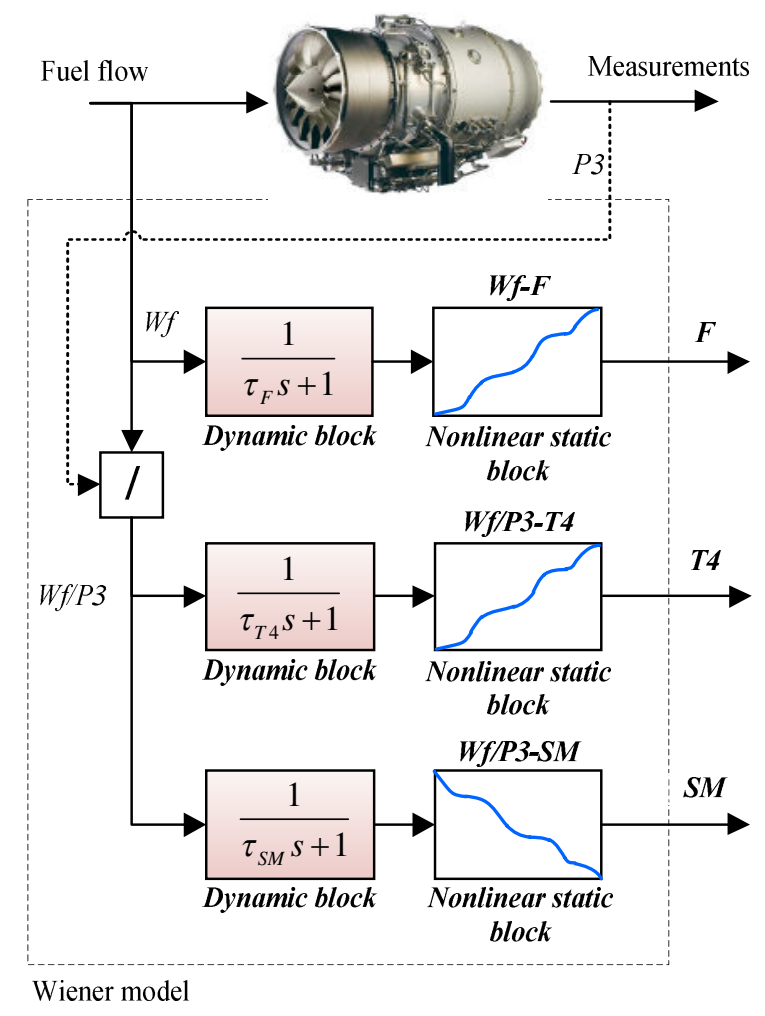

Fig. 5 Wiener model configuration for nominal engines on-board modelling

The next step is the parameters tuning of Wiener model for gas turbine engines on-board modelling. 
The nonlinear static block could be represented as the steady operating lines of the engine $[49,50]$. The engine steady operating lines are usually obtained through experiments or the validated aerothermal engine model. For the safety-critical parameters (i.e. thrust (F), turbine entry temperature (T4) and surge margin (SM)) concerned in this study, the corresponding steady-state operating lines of the engine are defined as Eqs. (7)-(9), respectively.

$$
\begin{gathered}
F=f_{1}(W f) \\
T 4=f_{2}(W f / P 3) \\
S M=f_{3}(W f / P 3)
\end{gathered}
$$

Meanwhile, the linear dynamic blocks in Wiener model is described as a first-order transfer function to illustrate the lag response in engine transient states, as shown in Eq. (10),

$$
G_{i}(s)=\frac{1}{\tau_{i} s+1}
$$

where $\tau_{i}$ is the "time constant" for the parameter of interest and $s$ denotes the complex variable. It should be noted that the transfer function in Wiener model is different from the transfer function that is utilized to represent the dynamic behavior in a local operating region of gas turbine engines [20, 51].

In order to provide the best transient performance of Wiener model in transient states, the linear dynamic blocks are computed by an optimization approach from the engine transient state data. The objective functions for the time constant in linear dynamic blocks of thrust $(\mathrm{F})$, turbine entry temperature (T4), and surge margin (SM), are defined in Eqs. (11)-(13). The time constant for thrust is optimized by the minimum of the error integration between estimated thrust $F_{\text {est }}$ and real thrust $F_{\text {real }}$ in both acceleration and deceleration states within a simulation time span $t$, as shown in Eq. (11). 
However, the objective functions for T4 and SM mainly focus on the acceleration states because these two parameters run closer to their limits in rapid transients. In Eq. (12), the first part calculates the integration error between the estimated $\mathrm{T} 4\left(T 4_{\text {est }}\right)$ and real $\mathrm{T} 4\left(T 4_{\text {real }}\right)$. The second part concentrates on the mismatch between the maximal T4 estimation $\left(T 4_{\text {est, } \max }\right)$ and maximal real T4 $\left(T 4_{\text {real, } \max }\right)$. The weights, $w_{1}$ and $w_{2}$, are used here to numerically tune the two parts in the same order. The objective function of surge margin has the same style as that of T4. The first element in Eq. (13) focuses on the integration error between the estimated surge margin $\left(S M_{e s t}\right)$ and real surge margin $\left(S M_{\text {real }}\right)$, while the second element computes the gap between the minimum estimated surge margin $\left(S M_{e s t, \text { min }}\right)$ and the minimum real surge margin $\left(S M_{\text {real, } \min }\right)$. The weights, $w_{3}$ and $w_{4}$, are also applied to make the two parts in a similar amplitude. In Eqs. (12) and (13), tacc represents acceleration time.

$$
\begin{gathered}
J_{F}=\int_{0}^{t} \frac{F_{\text {est }}-F_{\text {real }}}{F_{\text {real }}} d t \\
J_{T 4}=w_{1} \int_{0}^{t_{a c c}} \frac{T 4_{\text {est }}-T 4_{\text {real }}}{T 4_{\text {real }}} d t+w_{2} \frac{T 4_{\text {est,max }}-T 4_{\text {real, max }}}{T 4_{\text {real }, \text { max }}} \\
J_{S M}=w_{3} \int_{0}^{t_{a c c}} \frac{S M_{e s t}-S M_{\text {real }}}{S M_{\text {real }}} d t+w_{4} \frac{S M_{e s t, \text { min }}-S M_{\text {real }, \text { min }}}{S M_{\text {real, min }}}
\end{gathered}
$$

\subsection{Simulation comparison}

In order to identify the best on-board model of nominal engines for control purposes, PWL model described in Table 3, NGDF model described in Fig. 3, and Wiener model described in Fig. 5 are tested on the turbofan engine aero-thermal model, as presented in Section two. The linear dynamic parts in Wiener model for the nominal turbofan engine are optimized via particle swarm optimization (PSO) 
[52], as illustrated in Table 4.

Table 4 Optimized values of linear dynamic parts in Wiener model for the nominal turbofan engine

\begin{tabular}{cccc}
\hline Parameters & Thrust & T4 & SM \\
\hline Time constant & 0.3954 & 0.2174 & 0.013 \\
\hline
\end{tabular}

A series of rapid acceleration and deceleration transient states between idle to full power at sealevel static were simulated for the examined turbofan engine, as shown in Fig. 6. The engine was represented by the validated turbofan engine aero-thermal model. The parameters, fuel flow, thrust, and turbine entry temperature, were normalized by the corresponding values in their take-off specifications, as presented in Table 1. As can be seen in Fig. 6(a), fuel flow (Wf) was varied in 1 second from idle to full power state, in the continuous form of ramp acceleration and deceleration. Wiener model showed the best tracking performance for thrust in both acceleration and deceleration states, as depicted in the zooming plot in Fig. 6(b). The results in Fig. 6(c) and Fig. 6(d) indicate that NGDF model showed undesirable error accumulation for turbine entry temperature (T4) and surge margin of HPC. In terms of the overshoot in T4 and the undershoot in SM at the end of acceleration states (e.g. at $51 \mathrm{~s}$ in Fig. 6(c) and at $31 \mathrm{~s}$ Fig. 6(d)), the performance of Wiener model showed the best agreement with the real engine. The T4 overshoot and SM undershoot from PWL model is too excessive, which will be too conservative for engine transient performance, if the estimates from PWL model were feedback to the control system. Although the transient accuracy from Wiener model for surge margin and T4 at the end of deceleration states (e.g. at $60 \mathrm{~s}$ in Fig. 6(c) and Fig. 6(d)) seems 
undesirable, it is still acceptable. This is based on the fact that the engine at deceleration states operates far away from its surge line and over-temperature limit.

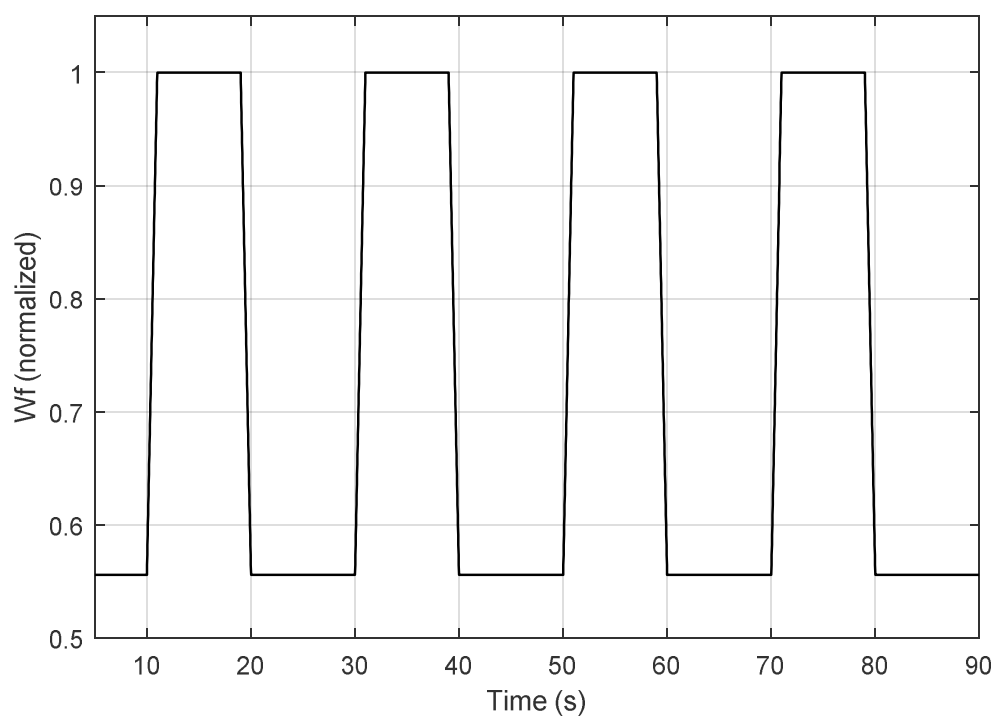

(a) Fuel flow

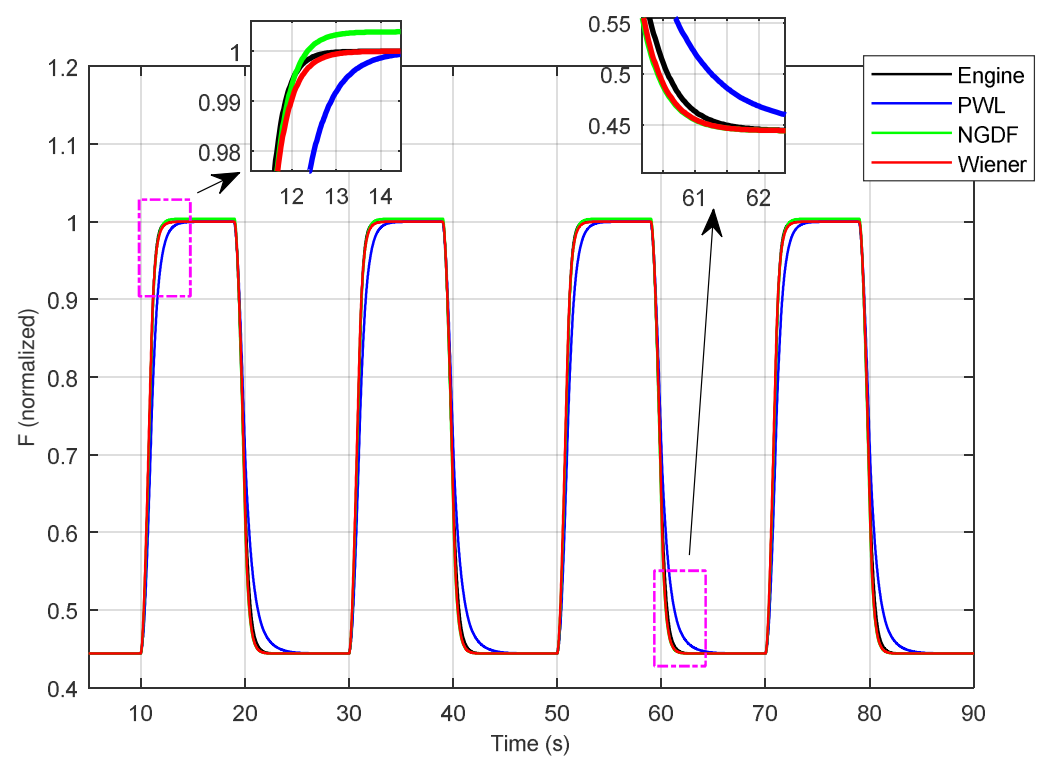

(b) Thrust 


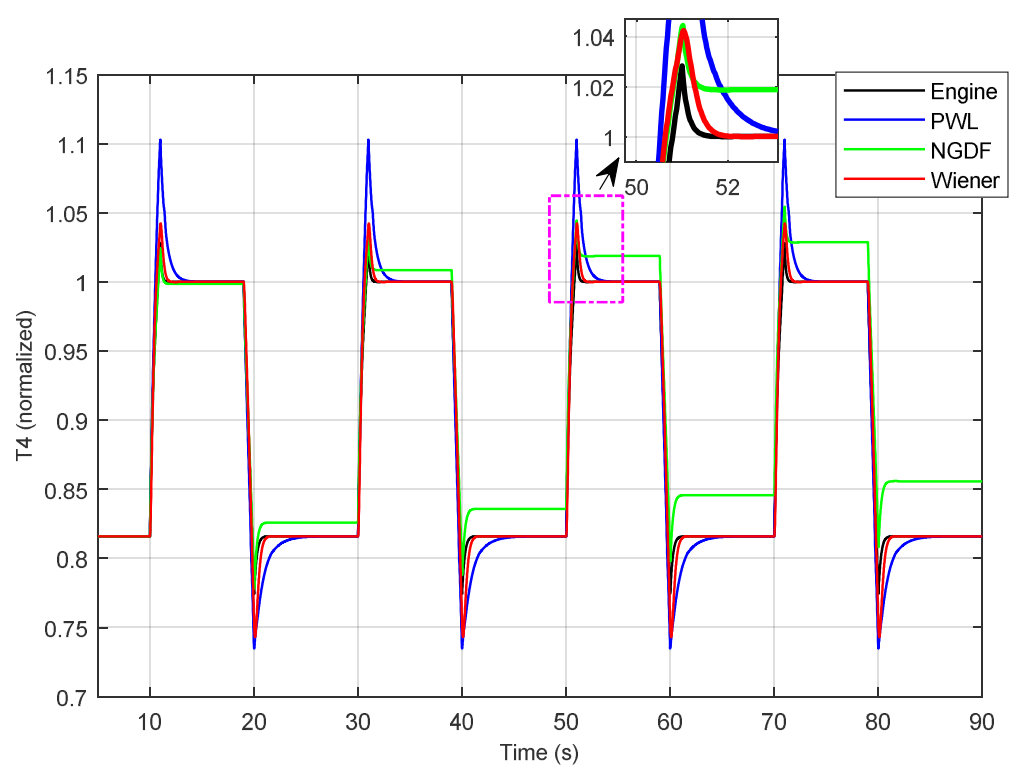

(c) Turbine entry temperature

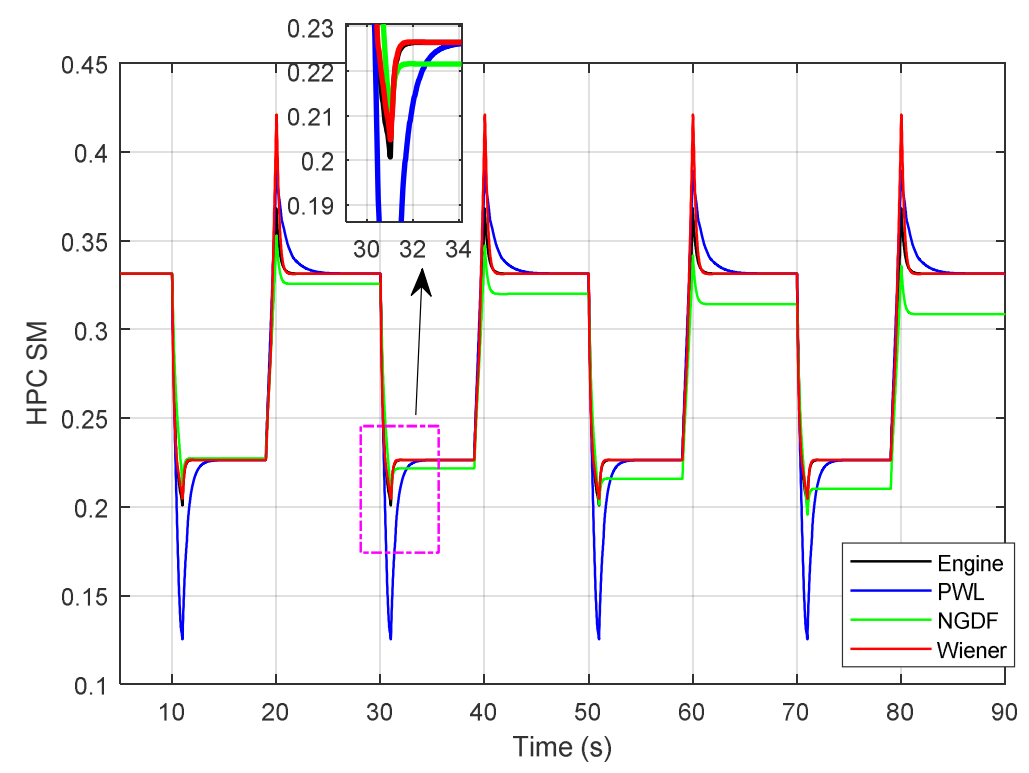

(d) Surge margin of HPC

Fig. 6 Comparison of on-board models simulations for the nominal turbofan engine

Moreover, the steady error and maximal transient error of PWL, NGDF, and Wiener model against the turbofan engine were compared, as illustrated in Table 5. The steady error was computed in steady states as a percent error between each on-board model and the aero-thermal engine model. The 
maximal transient error for thrust was calculated during both acceleration and transient states. However, the maximal transient error for T4 and SM were computed in only acceleration (Acc) states because the transient accuracy of T4 and SM are much more important during acceleration where the engine runs closer to its surge limit and over-temperature limit. NGDF owns diverged steady error and transient error for T4 and SM so that it is passed firstly. PWL and Wiener model both have very high steady accuracy due to the static element behind their structure. Given the transient accuracy for thrust, T4, and SM, Wiener model outperforms PWL model.

Table 5 Comparisons on the steady error and maximal transient error of PWL, NGDF and Wiener model

\begin{tabular}{ccccc}
\hline \multirow{2}{*}{ Model } & \multirow{2}{*}{ Steady error } & \multicolumn{3}{c}{ Maximal transient error (\%) } \\
\cline { 3 - 5 } & & Thrust & T4 (in Acc) & SM (in Acc) \\
\hline PWL & No & 14.53 & 7.29 & 37.55 \\
NGDF & Diverge & 5.72 & Diverge & Diverge \\
Wiener & No & 6.20 & 5.93 & 3.91 \\
\hline
\end{tabular}

Therefore, it is concluded that Wiener model is the best candidate for nominal engines on-board modelling when unmeasured parameters, thrust, T4, and surge margin are concerned. However, due to the normal aging of gas turbine engines from erosion, corrosion, fouling, and tip clearance change over the life cycle, the engine performance deviates from its nominal state. Nominal engines on-board model could not provide accurate information for a particular degraded engine. Hence, on-board modelling for degraded engines over the life cycle is investigated in the following sub-section. 


\section{Hybrid Wiener model}

An on-board modelling approach for gas turbine aero-engines using post-flight data, Hybrid Wiener model (HWM), is proposed, as an enhancement of Wiener model that was identified as the best candidate for nominal engines. The modelling details of HWM are presented in this section.

\subsection{HWM structure}

The proposed Hybrid Wiener model integrates an on-line part with an off-line part to adapt to the degradation effects over the engine life cycle, as illustrated in Fig. 7. The on-line part is simulated by Wiener model to calculate the unmeasured safety-critical parameters, i.e. thrust, turbine entry temperature, and surge margin, in a real time manner, as described in Fig. 5. Oppositely, the off-line part takes advantage of post-flight engine data to behave as an adaptation approach for the periodical update of the engine's steady-state operating lines (SS Op-Line) in the nonlinear static element of its corresponding on-line counterpart, Wiener model. As such, this hybrid model endeavors to work in the vicinity of degraded engines to the most possible extent. The off-line adaptation details are presented in the next sub-section. 


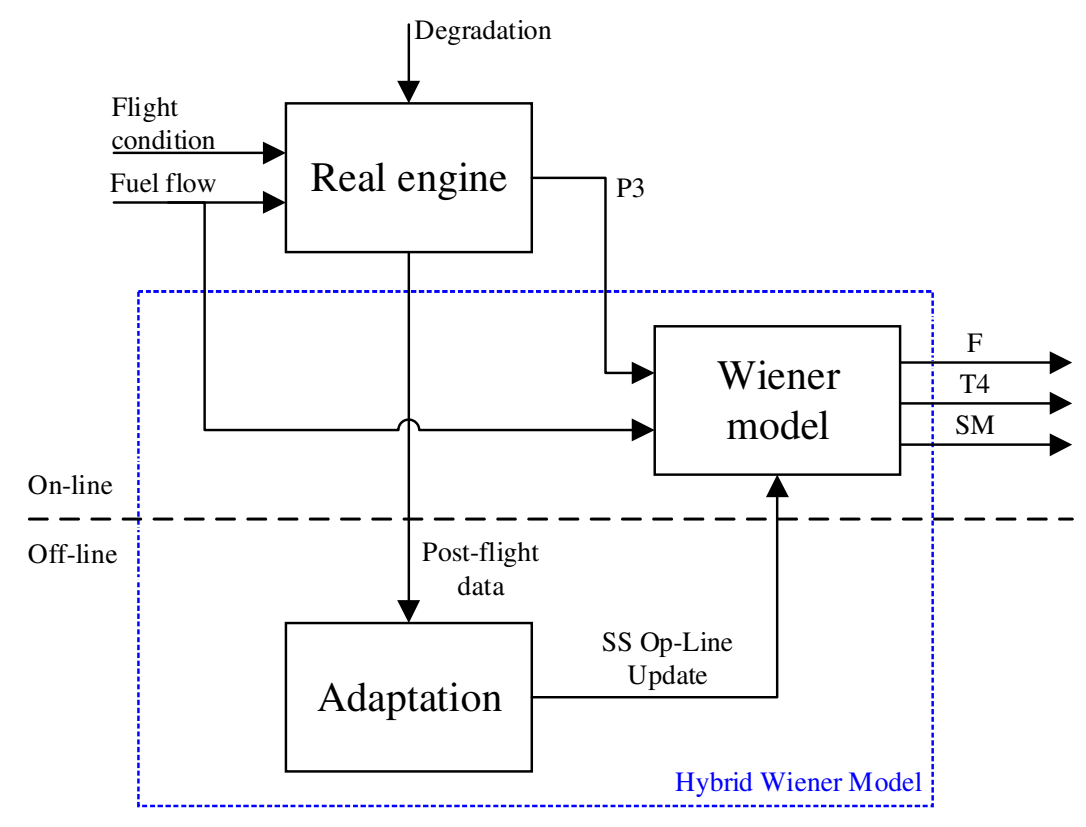

Fig. 7 Schematic of Hybrid Wiener model for degraded engines on-board modelling

\subsection{Off-line adaptation approach}

The off-line adaptation approach in HWM relies on the engine post-flight data and the aerothermal engine model to periodically update the steady-state operating lines behind Wiener model, as illustrated in Fig. 8. This is achieved by two steps. The first step is the health parameters estimation to track the gas path component performance due to degradation effects, while the second walk is to generate updated steady-state operating lines. An assumption for the off-line adaptation block is that the health status of a monitored engine is approximately equivalent within two consecutive flight cycles under gradual degradation effects, as shown in Table 2. Hence, the off-line adaptation element updates the health parameters and steady-state operating lines after each flight cycle to match the specified engine with the most possible effort.

In the first step, the steady-state measurements (i.e. under cruise state) in engine post-flight data 
and the estimated measurement from the aero-thermal model form an objective function, as defined in Eq. (14), where $y$ denotes steady-state measurements in post-flight engine data, $\hat{y}$ is the estimated measurements from the aero-thermal model and $M$ is the total number of measurements. The aerothermal engine model here should be the validated model for nominal conditions (i.e. for new or clean engines). The objective function is minimized by an optimization method. Since previous studies have confirmed that meta-heuristic global optimization algorithms show the superior performance in gas path component performance tracking for degradation effects [7, 53], particle swarm optimization (PSO) [52], as a powerful global optimization tool, is selected in this study. Once the objective function is minimized, the accurate health parameters are therefore obtained. In order to tackle the repeatability issue behind global optimization algorithms, running results of several repeated rounds from PSO are averaged to get a more reliable health parameters estimation. Finally, the updated SS Op-lines are constructed by inserting the estimated health parameters to the aero-thermal engine model. Meanwhile, linear dynamic blocks behind Wiener model are hold constant as those of nominal engines, as optimized in Table 4. The reason behind this updating mechanism is discussed in detail via simulation cases in the next section. 


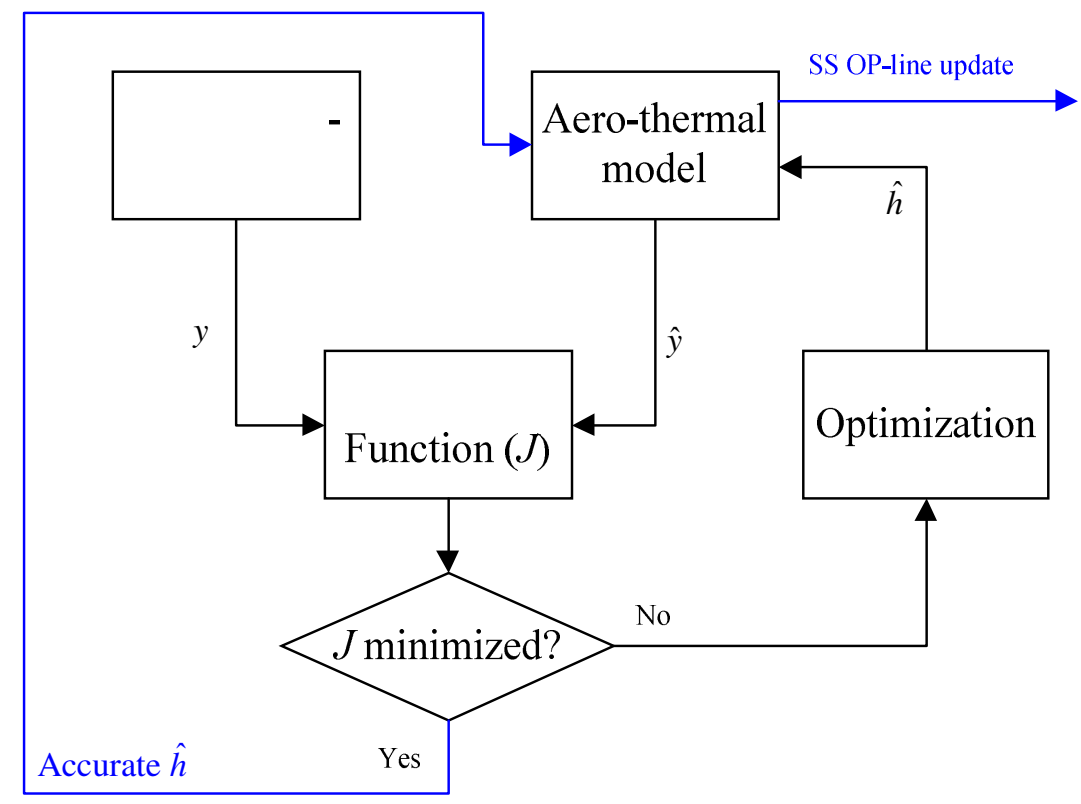

Fig. 8 Flowchart of the off-line adaptation approach in HWM

$$
J=\frac{1}{M} \sum_{i=1}^{M}\left|\frac{\hat{y}-y}{y}\right| \cdot 100
$$

Health parameters and measurements for the examined turbofan engine are illustrated in Table 6 and Table 7, respectively. The health parameters of pressure ratio for fan and HPC are implicitly embedded, as defined in Eq. (4), so that the total number of eight health parameters needs to be adapted. The measurements utilized in the off-line adaptation are low-pressure spool speed (N1), highpressure spool speed (N2), fuel flow (Wf), and other available temperature/pressure signals in the gas path.

Table 6 Health parameters for target turbofan engine

\begin{tabular}{lc}
\hline Health parameters & Symbol \\
\hline Fan efficiency & $\Delta \eta_{F a n}$ \\
Fan flow capacity & $\Delta \Gamma_{F a n}$ \\
Fan pressure ratio (implicit) & $\Delta \pi_{F a n}$ \\
HPC efficiency & $\Delta \eta_{H P C}$ \\
\hline
\end{tabular}




\begin{tabular}{ll}
\hline HPC flow capacity & $\Delta \Gamma_{H P C}$ \\
HPC pressure ratio (implicit) & $\Delta \pi_{H P C}$ \\
HPT efficiency & $\Delta \eta_{H P T}$ \\
HPT flow capacity & $\Delta \Gamma_{H P T}$ \\
LPT efficiency & $\Delta \eta_{L P T}$ \\
LPT flow capacity & $\Delta \Gamma_{L P T}$ \\
\hline
\end{tabular}

Table 7 Measurements in target turbofan engine post-flight data

\begin{tabular}{ll}
\hline Measurements & Symbol \\
\hline Low-pressure spool speed & $\mathrm{N} 1$ \\
High-pressure spool speed & $\mathrm{N} 2$ \\
Fan outlet total temperature & $\mathrm{T} 21$ \\
Fan outlet total pressure & $\mathrm{P} 21$ \\
HPC outlet total temperature & $\mathrm{T} 3$ \\
HPC outlet total pressure & $\mathrm{P} 3$ \\
HPT outlet total temperature & $\mathrm{T} 45$ \\
HPT outlet total pressure & $\mathrm{P} 45$ \\
LPT outlet total temperature & $\mathrm{T} 5$ \\
LPT outlet total pressure & $\mathrm{P} 5$ \\
Fuel flow & $\mathrm{Wf}$ \\
\hline
\end{tabular}

\section{Simulation results}

To verify the effectiveness of the proposed Hybrid Wiener model for gas turbine aero-engines onboard modelling over the life cycle, numerical simulations were carried on the turbofan engine aerothermal model for degradation simulations using publicly available data, as presented in Section two. Firstly, the performance of HWM is confirmed via a series of idle to full power rapid transient simulations for different degradation levels. Then, whether the linear dynamic blocks behind Wiener model would contribute to on-board modelling accuracy is discussed in detail. 
As the modelling details of HWM presented in Section four, the off-line adaptation mechanism is responsible for the accuracy enhancement for degraded engines on-board modelling. The update logic defined in Fig. 8 was applied to the examined turbofan engine aero-thermal model for degradation simulations. Health parameters for each flight cycle could be linearly interpolated from the degradation data in Table 2. Here, two degradation levels, 3000 flight cycles and 6000 flight cycles, were selected as a case study to represent middle-life and end-of-life engines. Then the post-flight engine data at steady states in the former flight cycle, i.e. 2999 flight cycles and 5999 flight cycles, were utilized to track the gas path component performance under gradual degradation effects and the update for corresponding steady-state operating lines. The off-line adaptation setting by PSO is shown in Table 8. Particularly, the search bound for health parameters estimation is defined from $-10 \%$ to $+10 \%$ of each corresponding actual health parameters, which are interpolated from Table 2, to provide an adequate confidence level. The results of 10 repeated runs from PSO are averaged for health parameters estimation.

Table 8 Off-line adaptation setting by PSO

\begin{tabular}{ll}
\hline Setting & Value \\
\hline Population size & 20 \\
Maximum generation & 100 \\
Repeated runs & 10 \\
Particle velocity bound & {$[-0.01,+0.01]$} \\
Health parameters bound & {$[-10 \%,+10 \%]$} \\
\hline
\end{tabular}

The estimation results for health parameters of the examined turbofan engine at 3000 and 6000 flight cycles are illustrated in Fig. 9. The publicly available degradation data were implanted into the 
aero-thermal turbofan model to represent the degraded engine performance, as presented in Table 2. As clarified in Section 4.2, the post-flight engine data from the former flight cycle are applied in the off-line adaptation element. Here, the steady-state measurements under the cruise stage at 2999 flight cycles and 5999 flight cycles were utilized. It is clearly shown in Fig. 9(a) that all the health parameters estimation matches well with their implanted values for the engine at 3000 flight cycles, while a relative mismatch for the health parameter of fan isentropic efficiency, $\Delta \eta_{\text {Fan }}$. For the studied turbofan engine under 6000 flight cycles, although the health parameters estimation for isentropic efficiency of fan $\Delta \eta_{F a n}$ and LPT $\Delta \eta_{L P T}$ demonstrate a minor mismatch to their implanted values, other health parameters estimation shows a good agreement with their implantation, as shown in Fig. 9(b).

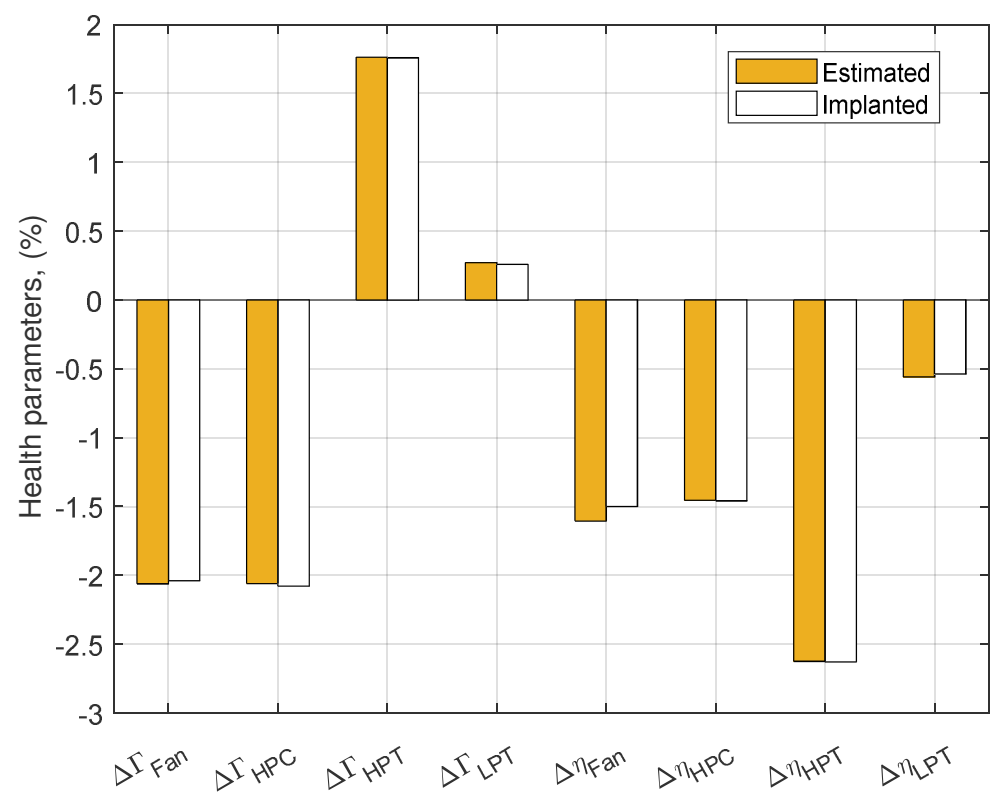

(a) 3000 flight cycles 


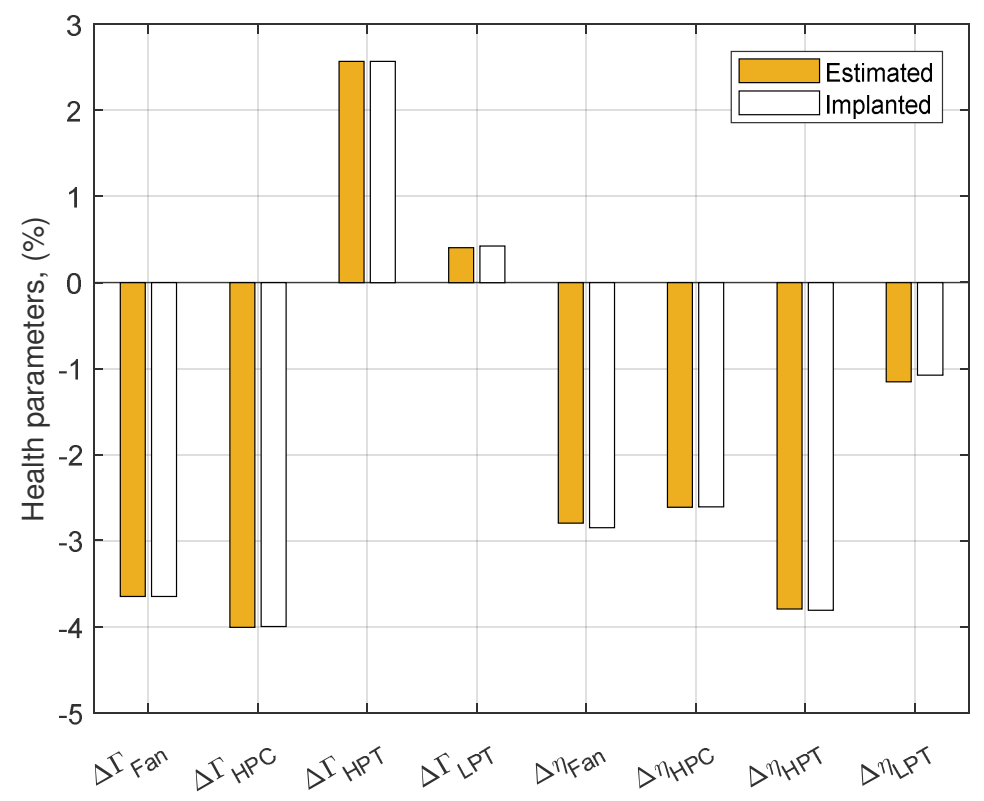

(b) 6000 flight cycles

Fig. 9 Health parameters estimation via the off-line adaptation approach

Subsequently, the updated steady-state operating lines were created from the aero-thermal turbofan engine model after each flight in an off-line manner. This was accomplished by the aerothermal engine model, in which the estimated degraded component maps were generated via the health parameters estimation, as defined in Eqs. (1)-(4).

With the updated SS Op-Line and the optimized values of the linear dynamic parts, as shown in Table 4, the Hybrid Wiener model was tested for the target turbofan engine over the life cycle. Idle to full power rapid transient state simulations at sea level static condition for the turbofan engine at nominal condition, 3000 flight cycles, and 6000 flight cycles were conducted. The idle and full power state of the examined engine was set as their corresponding thrust setpoints, engine pressure ratio (EPR), which are 1.1003 and 1.1890 , respectively.

Fig. 10 shows the Hybrid Wiener model simulation results for the idle to full power rapid transients 
of the studied turbofan engine under nominal conditions, 3000 flight cycles (FC) and 6000 flight cycles. The engine was represented by the aero-thermal turbofan model for degradation simulations, as presented in Section two. Thrust and turbine entry temperature in this simulation were normalized with their take-off specifications of the nominal turbofan engine, as defined in Table 1. Fig. 10(a) indicates that the thrust estimation from HWM tracks well with the real engine, even under different degradation levels, during these rapid transients, while the steady error is almost eliminated due to the effort of the off-line adaptation behind HWM. The maximum percent error of thrust between HWM and the engine in the acceleration state is $4.66 \%$, even at 6000 flight cycles, as shown in Fig. 10(b). It can be seen that a relatively noticeable transient mismatch for thrust at the ending acceleration stage (i.e. at $15 \mathrm{~s}$ ). The reason behind this mismatch is the optimization approach of the linear dynamic block for thrust, which is intended to balance acceleration and deceleration modelling accuracy, as presented in Eq. (11). From Fig. 10(c), it is concluded that HWM shows a quite favourable tracking performance for turbine entry temperature (T4) during acceleration states, even for the overshoot of T4 during the ending acceleration stage. The steady error for T4 is also nearly eliminated. The maximum transient error for T4 is about 3.03\%, as illustrated in Fig. 10(d). As is presented in Fig. 10(e), the HWM transient performance for HPC surge margin matches well with the real engine at 3000 and 6000 flight cycles, even for the peak value in the undershoot of the surge margin during this acceleration states. Steady error for surge margin also approximately equals to zero, while the maximum percent error for surge margin is less than $4.25 \%$ for all degradation levels, as depicted in Fig. 10(f). 


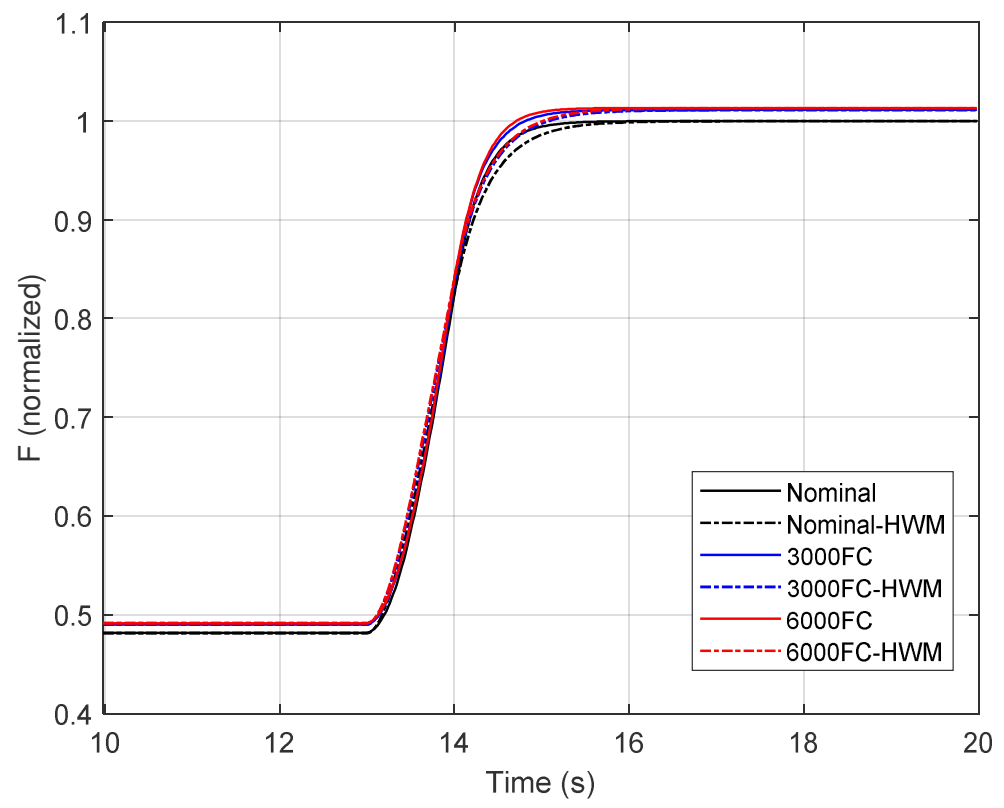

(a) Thrust

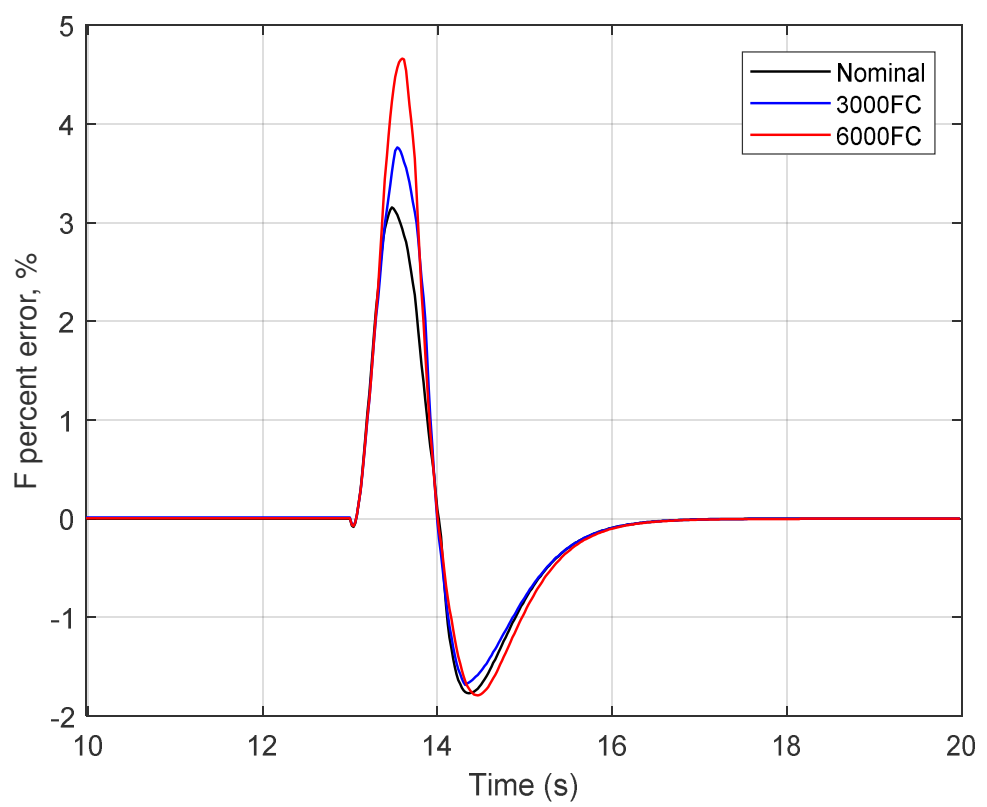

(b) Percent error of thrust 


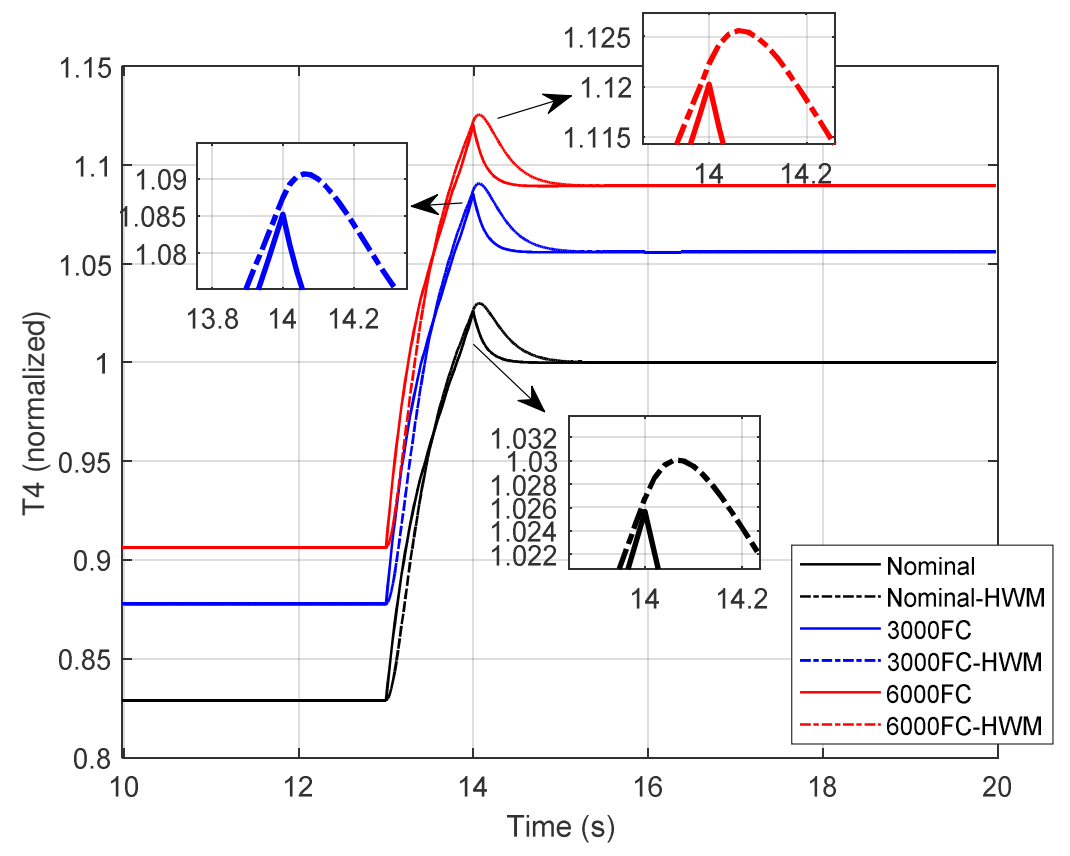

(c) Turbine entry temperature

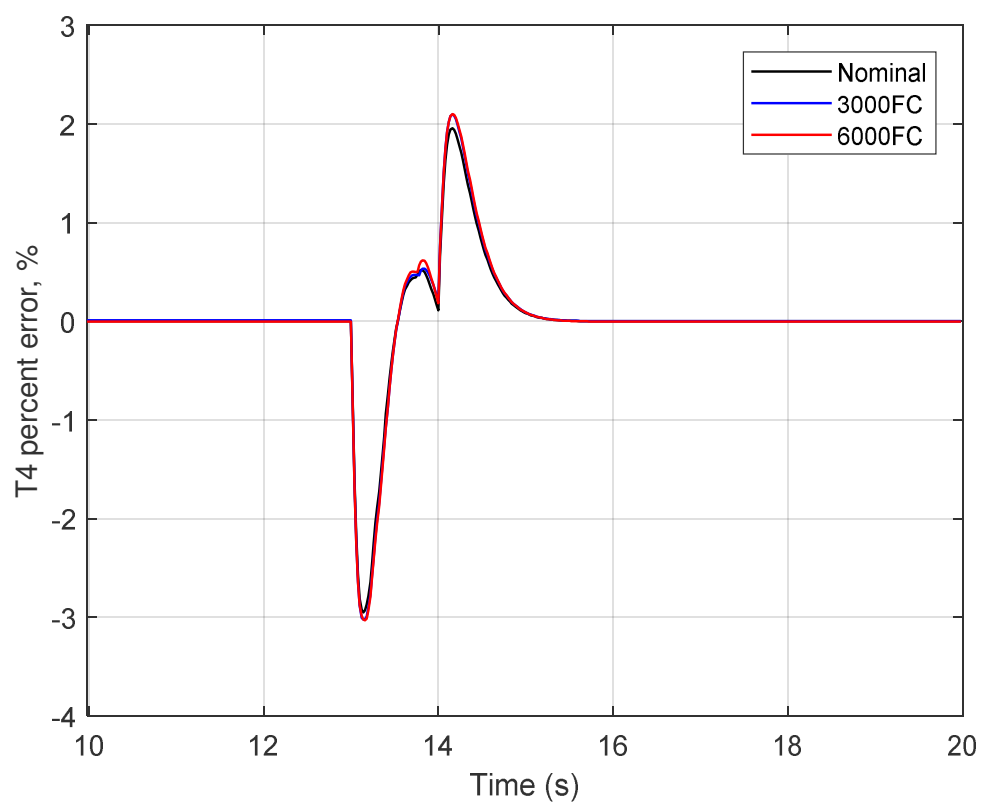

(d) Percent error of turbine entry temperature 


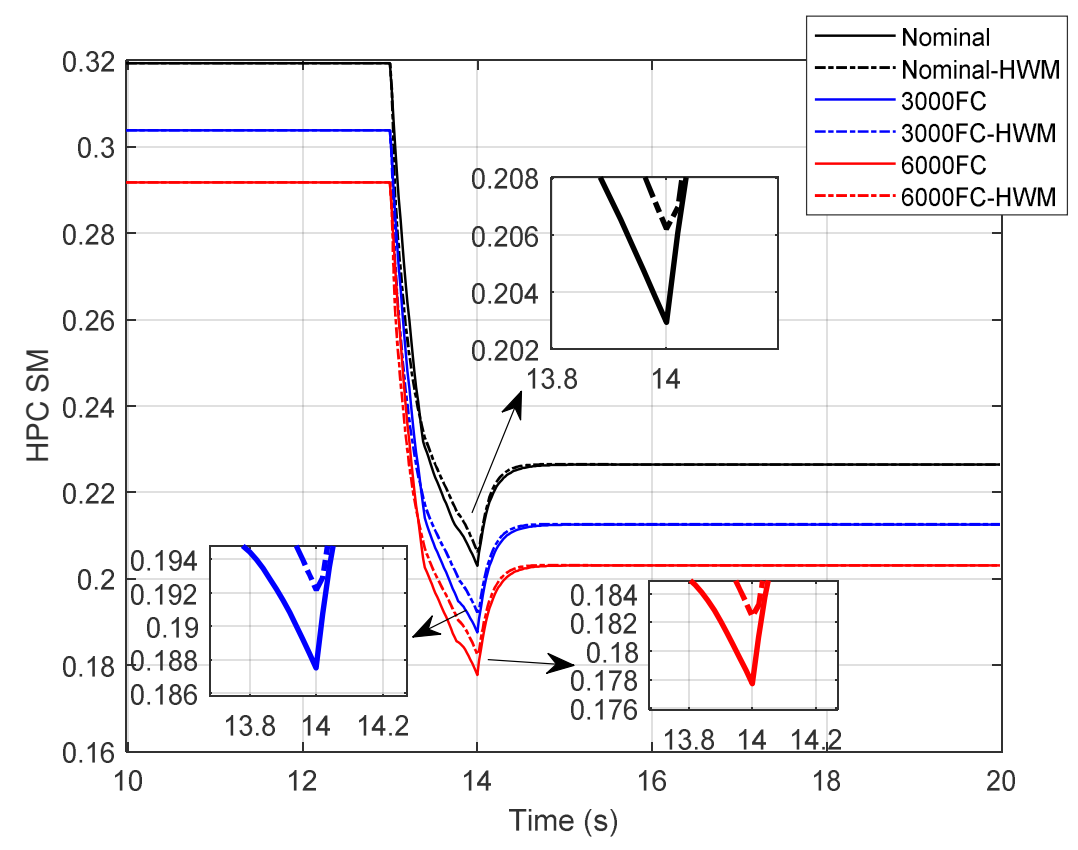

(e) HPC surge margin

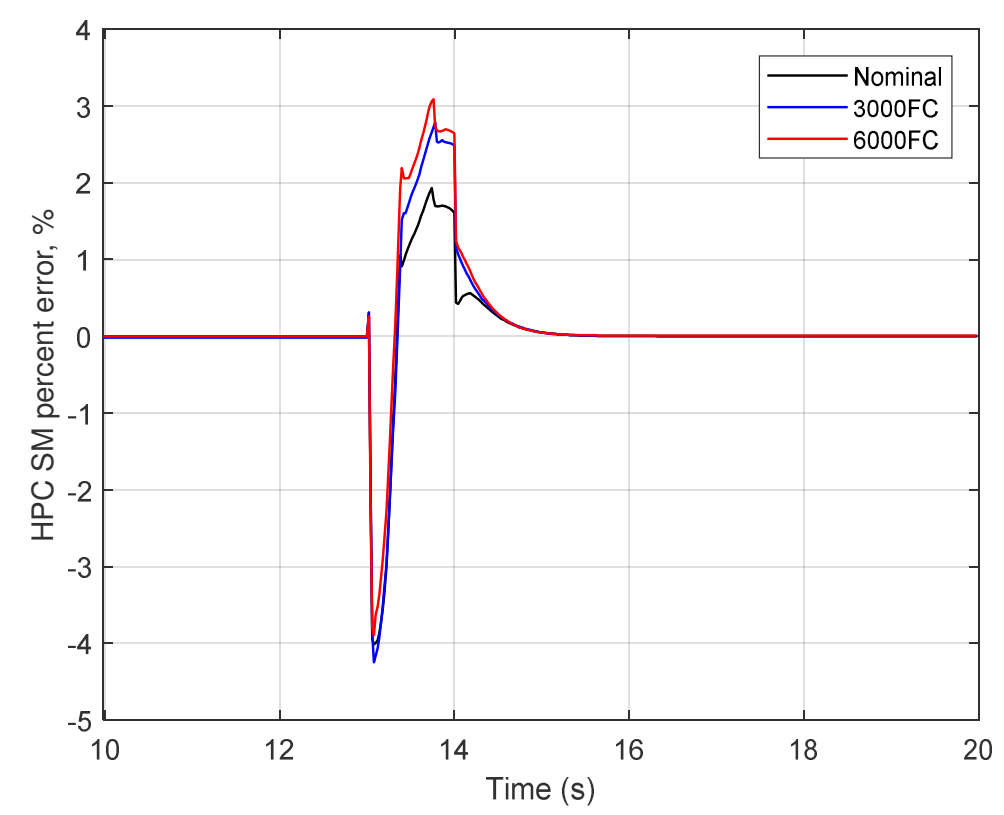

(f) Percent error of HPC surge margin

Fig. 10 Idle to full-power simulations of HWM for the target turbofan engine over the life cycle

Moreover, the peak values of turbine entry temperature and HPC surge margin between HWM and the real engine during this rapid acceleration states are compared in Table 9, because of the design 
focus in the gas turbine engines control system that the engine runs closer to its over-temperature and surge margin limit during acceleration transients. All the percent error for maximum T4 value are below $0.5 \%$, while the percent error for minimum surge margin are less than $0.47 \%$ for all degradation levels.

Table 9 Comparison on the turbine entry temperature and surge margin peak values between HWM and the engine during

\begin{tabular}{ccccccc}
\multicolumn{8}{c}{ rapid acceleration states } \\
\hline \multirow{2}{*}{$\begin{array}{c}\text { Flight } \\
\text { cycle }\end{array}$} & Engine & HWM & $\begin{array}{c}\text { Percent } \\
\text { error, (\%) }\end{array}$ & Engine & HWM & $\begin{array}{c}\text { Percent } \\
\text { error, (\%) }\end{array}$ \\
\cline { 2 - 7 } 0 & 1.0257 & 1.0300 & 0.42 & 0.2029 & 0.2062 & 0.33 \\
3000 & 1.0852 & 1.0906 & 0.50 & 0.1875 & 0.1922 & 0.47 \\
6000 & 1.1202 & 1.1256 & 0.48 & 0.1777 & 0.1824 & 0.47 \\
\hline
\end{tabular}

Another interesting question is that whether the update for the linear dynamic part (i.e. the time constant) could further enhance the accuracy of the Hybrid Wiener model. The examined turbofan engine at 3000 flight cycles was tested. Table 10 lists fixed and updated linear dynamic parts in HWM. Values for fixed time constant are the same as those in Table 4. Parameters for updated time constant in Table 10 were calculated based on the transient data in the previous flight cycle (2999 flight cycles) and the objective functions defined in Eqs. (11)-(13). As is observed in Fig. 11, fixed and updated linear dynamic parts in HWM from idle to full-power at sea level static were simulated. The steadystate operating lines were updated from the former flight cycle for both simulation cases. Thrust and turbine entry temperature here were normalized with their take-off specifications defined in Table 1. Fig. 11(a) indicates that HWM with updated time constant shows a quite limited improvement for 
thrust tracking compared to HWM with fixed time constant. There is a similar phenomenon that HWM with updated linear dynamic parts does not gain too much benefit regarding the peak values for T4 and SM, as are depicted in Fig. 11(b) and Fig. 11(c). Moreover, the optimization in the time constant update requires additional computational burden. This is consistent with the previous studies which confirmed that degradation effects have major influence on the steady-state performance of gas turbine engines $[54,55]$. Hence, the effectiveness of Hybrid Wiener model with steady-state operating lines update and constant linear dynamic blocks is confirmed.

Table 10 Constant and updated linear dynamic parts in HWM for the engine at 3000 flight cycles

\begin{tabular}{ccc}
\hline \multirow{2}{*}{ Parameters } & \multicolumn{2}{c}{ Time constant } \\
\cline { 2 - 3 } & fixed & updated \\
\hline Thrust & 0.3954 & 0.4025 \\
T4 & 0.2174 & 0.2214 \\
SM & 0.013 & 0.0127 \\
\hline
\end{tabular}

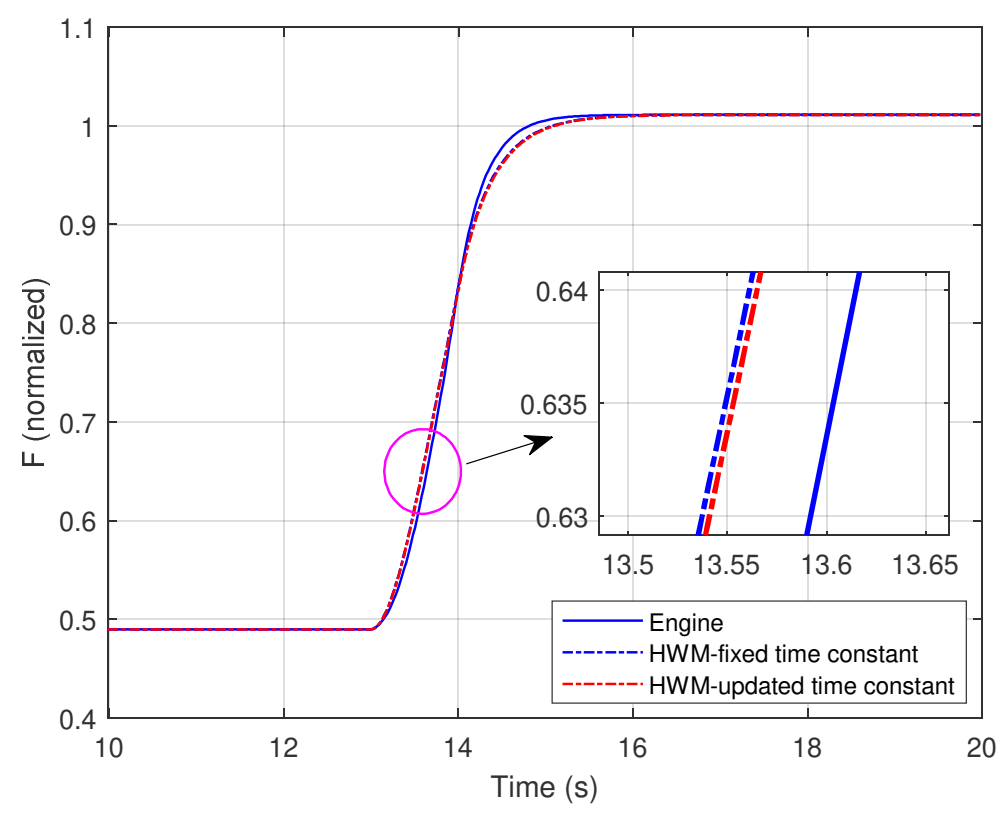

(a) Thrust 


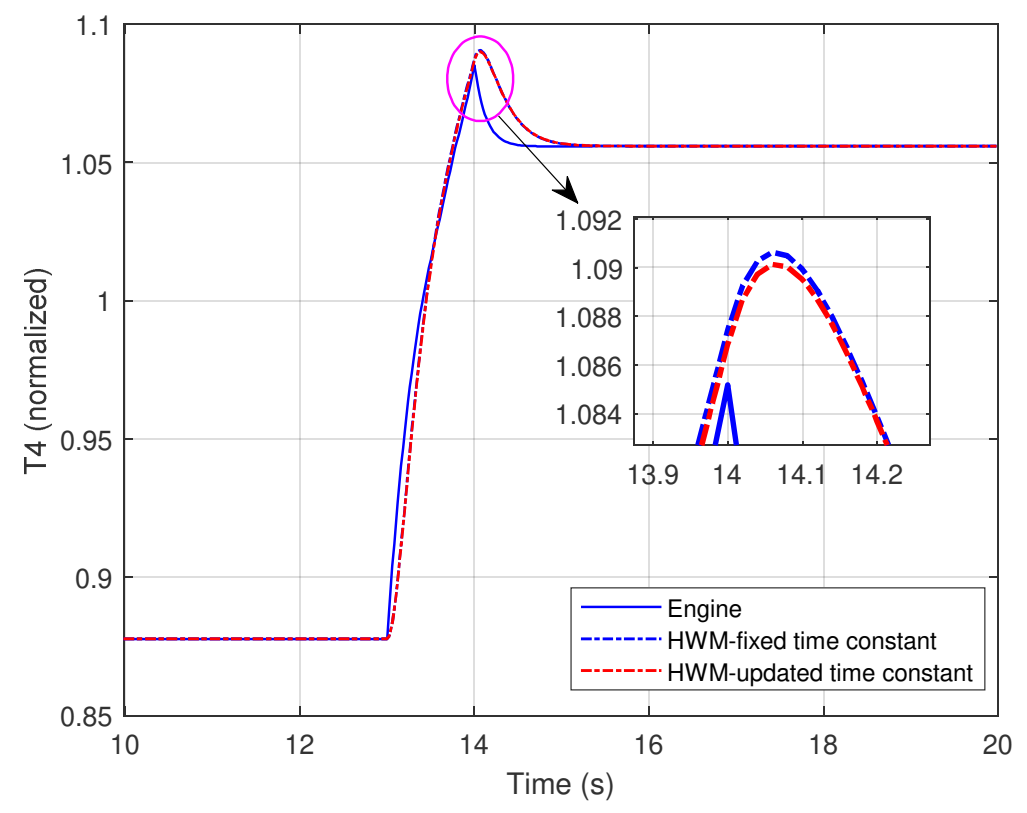

(b) Turbine entry temperature

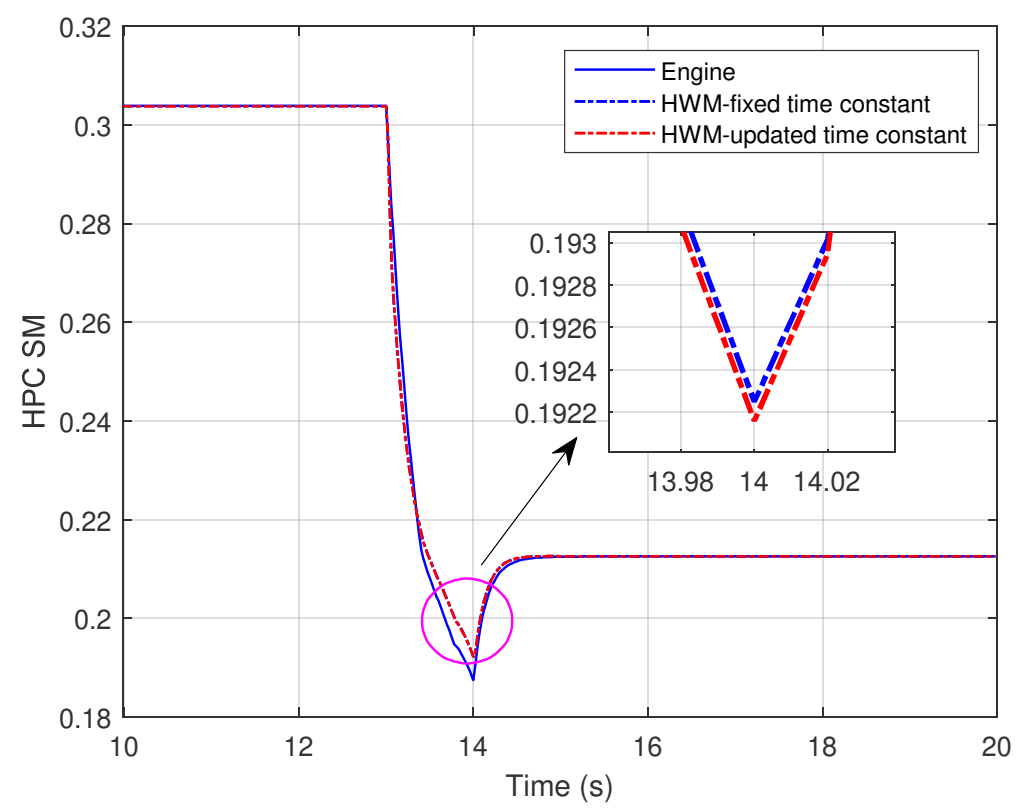

(c) HPC surge margin

Fig. 11 Comparison on the fixed and updated linear dynamic parts in HWM for the engine at 3000 flight cycles

Practically, measurements in the flight data are always subject to sensor noise which may mask the true health condition of the monitored engine. However, the primary focus of this work is to purely 
concentrate on the engine health tracking and unmeasured parameters estimation as a methodological approach. Hence, sensor noise has not been taken into account. Several noise reduction approaches, such as exponential average, Kalman filter, and neural network, could be utilized in combination with the proposed HWM to guarantee a reliable dataset [56].

\section{Conclusions}

In this paper, an on-board modelling approach using post-flight data, named Hybrid Wiener model, was proposed for gas turbine aero-engines. HWM endevours to estimate unmeasured safety-critical control parameters (i.e. thrust, surge margin and turbine entry temperature) via monitoring the engine health status. To evaluate the proposed model, a turbofan engine aero-thermal model for nominal condition was firstly developed and verified against experimental results. Degradation simulations of the turbofan engine aero-thermal model were extended using publicly available data of gas path components degradation. In order to identify the best on-board model for nominal engines, common on-board models for nominal engines, piecewise linear model, novel generalized describing function, and Wiener model, were carefully tested on the validated turbofan engine aero-thermal model. Simulations on a series of rapid acceleration and deceleration confirmed that Wiener model is the best candidate for nominal engines in terms of the steady accuracy and transient tracking performance for these unmeasured safety-critical parameters.

HWM was therefore inspired as an extension of Wiener model with an off-line part using postflight data. The main conclusions for HWM are (1) The on-line part, Wiener model, calculates the 
unmeasured thrust, surge margin, and turbine entry temperature in a real-time manner. (2) The off-line part is an adaptation approach using post-flight data to periodically update the nonlinear steady blocks (i.e. engine steady-state operating lines) in Wiener model for degraded engines. Via the minimum mismatch of the measurements between the engine post-flight data and aero-thermal engine model after every flight cycle, the engine health parameters as well as engine steady-state operating lines in Wiener model are updated. (3) The linear dynamic blocks in Wiener model require no update even for degraded engines. This was also verified on the simulation results on a degraded turbofan engine aerothermal model.

Simulations on the turbofan engine aero-thermal model with degradation effects showed that HWM owns both favourable steady and transient accuracy for thrust, surge margin, and turbine entry temperature during the idle to full power rapid transient states at different flight cycles. The steady accuracy of HWM is guaranteed by the off-line adaptation mechanism. The maximal transient errors for these safety-critical parameters are less than 4.66\%. Meanwhile, the percent errors of peak values for surge margin and turbine entry temperature between HWM and the engine are within $0.50 \%$. The successful performance of HWM enables the potential development of advanced model-based control strategies for gas turbine aero-engines. Further research on HWM will be extended to the full flight envelope and be accounted for the sensor/actuator dynamics.

\section{Acknowledgement}

This work is supported by China Scholarship Council (201906020115). 


\section{Reference}

[1] S. Garg, Aircraft Turbine Engine Control Research at NASA Glenn Research Center, J. Aerosp. Eng., 26 (2013) 422-438.

[2] Z.S. Spakovszky, J.B. Gertz , O.P. Sharma, J.D. Paduano , A.H. Epstein , E.M. Greitzer, Influence of Compressor Deterioration on Engine Dynamic Behavior and Transient Stall-Margin, J. Turbomach., 122 (1999) 477-484.

[3] S. Tang, H. Tang, M. Chen, Transfer-learning based gas path analysis method for gas turbines, Appl. Therm. Eng., 155 (2019) 1-13.

[4] M. Bai, J. Liu, J. Chai, X. Zhao, D. Yu, Anomaly detection of gas turbines based on normal pattern extraction, Appl. Therm. Eng., 166 (2020) 114664.

[5] J. Li, Y. Ying, Gas turbine gas path diagnosis under transient operating conditions: A steady state performance model based local optimization approach, Appl. Therm. Eng., 170 (2020) 115025.

[6] J. Liu, Z. Li, H. Hanachi, A physics-based framework for online surface roughness assessment for high-pressure turbines, Chin. J. Aeronaut., (2020).

[7] M. Tahan, E. Tsoutsanis, M. Muhammad, Z.A. Karim, Performance-based health monitoring, diagnostics and prognostics for condition-based maintenance of gas turbines: A review, Appl. Energy, 198 (2017) 122-144.

[8] J.S. Litt, D.L. Simon, S. Garg, T.-H. Guo, C. Mercer, R. Millar, A. Behbahani, A. Bajwa, D.T. Jensen, A survey of intelligent control and health management technologies for aircraft propulsion systems, J. Aerosp. Inf. Syst., 1 (2004) 543-563.

[9] H. Hanachi, C. Mechefske, J. Liu, A. Banerjee, Y. Chen, Performance-Based Gas Turbine Health Monitoring, Diagnostics, and Prognostics: A Survey, IEEE Trans. Reliab., 67 (2018) 1340-1363.

[10] C. Wang, Y.G. Li, B.Y. Yang, Transient performance simulation of aircraft engine integrated with fuel and control systems, Appl. Therm. Eng., 114 (2017) 1029-1037.

[11] H.A. Spang III, H. Brown, Control of jet engines, Control Eng. Pract., 7 (1999) 1043-1059.

[12] J. Connolly, A. Chicatelli, S. Garg, Model-Based Control of an Aircraft Engine using an Optimal Tuner Approach, Aiaa/asme/sae/asee Joint Propulsion Conference \& Exhibit, 2012.

[13] J.D. Flamm, K. James, J.T. Bonet, Overview Of ERA Integrated Technology Demonstration (ITD) 51A UltraHigh Bypass (UHB) Integration for Hybrid Wing Body (HWB) (Invited), 54th AIAA Aerospace Sciences Meeting2016.

[14] J.Y. Hung, L.F. Gonzalez, On parallel hybrid-electric propulsion system for unmanned aerial vehicles, Prog. Aerosp. Sci., 51 (2012) 1-17.

[15] A. Dinc, NOx emissions of turbofan powered unmanned aerial vehicle for complete flight cycle, Chin. J. Aeronaut., 33 (2020) 1683-1691.

[16] S. Adibhatla, S. Garg, S. Griffith, K. Karnofski, N. Payne, B. Wood, Propulsion Control Technology Development Roadmaps to Address NASA Aeronautics Research Mission Goals for Thrusts 3a and 4, 2018 Joint Propulsion Conference, 2018, pp. 4732.

[17] G.G. Kulikov, H.A. Thompson, Dynamic Modelling of Gas Turbines: Identification, Simulation, Condition Monitoring and Optimal Control, Springer-Verlag, London, 2004.

[18] J.B. Armstrong, D.L. Simon, Constructing an efficient self-tuning aircraft engine model for control and health management applications, Report No.: NASA/TM-2012-217806, Glenn Research Center, National Aeronautics and 
Space Administration, Cleveland, Ohio, 2012.

[19] N. Chiras, C. Evans, D. Rees, Nonlinear gas turbine modeling using NARMAX structures, IEEE Trans. Instrum. Meas., 50 (2001) 893-898.

[20] N. Chiras, C. Evans, D. Rees, Global nonlinear modeling of gas turbine dynamics using NARMAX structures, J. Eng. Gas Turbines Power, 124 (2002) 817-826.

[21] N. Chiras, C. Evans, D. Rees, Nonlinear Gas Turbine Modeling Using Feedforward Neural Networks, ASME Turbo Expo 2002: Power for Land, Sea, and Air, 2002, pp. 145-152.

[22] M. Lichtsinder, Y. Levy, Jet Engine Model for Control and Real-Time Simulations, J. Eng. Gas Turbines Power, 128 (2006) 745-753.

[23] S. Jafari, T. Nikolaidis, Meta-heuristic global optimization algorithms for aircraft engines modelling and controller design; A review, research challenges, and exploring the future, Prog. Aerosp. Sci., 104 (2019) 40-53.

[24] R. Luppold, J. Roman, G. Gallops, L. Kerr, Estimating in-flight engine performance variations using Kalman filter concepts, 25th Joint Propulsion Conference, 1989, pp. 2584.

[25] N. Sugiyama, System identification of jet engines, J. Eng. Gas Turbines Power, 122 (2000) 19-26.

[26] A. Kreiner, K. Lietzau, The use of onboard real-time models for jet engine control, Project Report OBIDICOTE, MTU Aero Engines, Munich, Germany, 2000.

[27] J.S. Litt, K.I. Parker, S. Chatterjee, Adaptive gas turbine engine control for deterioration compensation due to aging, NASA/TM-2003-212607, 2003.

[28] F. Lu, C. Jiang, J. Huang, X. Qiu, A multi-rate sensor fusion approach using information filters for estimating aero-engine performance degradation, Chin. J. Aeronaut., 32 (2019) 1603-1617.

[29] T. Kobayashi, D.L. Simon, Hybrid Kalman Filter Approach for Aircraft Engine In-Flight Diagnostics: Sensor Fault Detection Case, J. Eng. Gas Turbines Power, 129 (2006) 746-754.

[30] T. Kobayashi, D.L. Simon, Integration of On-Line and Off-Line Diagnostic Algorithms for Aircraft Engine Health Management, J. Eng. Gas Turbines Power, 129 (2007) 986-993.

[31] J.S. Litt, An Optimal Orthogonal Decomposition Method for Kalman Filter-Based Turbofan Engine Thrust Estimation, J. Eng. Gas Turbines Power, 130 (2008) 011601.

[32] D.L. Simon, S. Garg, Optimal Tuner Selection for Kalman Filter-Based Aircraft Engine Performance Estimation, J. Eng. Gas Turbines Power, 132 (2009) 031601.

[33] D. Simon, S. Garg, A systematic approach for model-based aircraft engine performance estimation, AIAA Infotech@ Aerospace Conference and AIAA Unmanned... Unlimited Conference, 2010, pp. 1872.

[34] J. Csank, J.W. Connolly, Model-Based Engine Control Architecture with an Extended Kalman Filter, AIAA Guidance, Navigation, and Control Conference, 2016.

[35] P.P. Walsh, P. Fletcher, Gas turbine performance, John Wiley \& Sons2004.

[36] J.W. Chapman, T.M. Lavelle, J.S. Litt, Practical Techniques for Modeling Gas Turbine Engine Performance, 52nd AIAA/SAE/ASEE Joint Propulsion Conference2016.

[37] A.J. Volponi, Gas turbine engine health management: past, present, and future trends, J. Eng. Gas Turbines Power, 136 (2014) 051201.

[38] Y.G. Li, Gas Turbine Performance and Health Status Estimation Using Adaptive Gas Path Analysis, J. Eng. Gas Turbines Power, 132 (2010) 041701.

[39] A.N. Lakshminarasimha, M.P. Boyce, C.B. Meher-Homji, Modeling and Analysis of Gas Turbine Performance Deterioration, J. Eng. Gas Turbines Power, 116 (1994) 46-52. 
[40] A.P. Tarabrin, V.A. Schurovsky, A.I. Bodrov, J.-P. Stalder, An Analysis of Axial Compressor Fouling and a Blade Cleaning Method, J. Turbomach., 120 (1998) 256-261.

[41] G. Reitz, A. Kellersmann, J. Friedrichs, Full High Pressure Compressor Investigations to Determine Aerodynamic Changes due to Deterioration, ASME Turbo Expo 2018: Turbomachinery Technical Conference and Exposition, 2018.

[42] E. Ramadhan, Y.-G. Li, D. Maherdianta, Application of Adaptive GPA to an Industrial Gas Turbine Using Field Data, ASME Turbo Expo 2019: Turbomachinery Technical Conference and Exposition, 2019.

[43] G. Sallee, Performance deterioration based on existing (historical) data; JT9D jet engine diagnostics program, Report No.: NASA-CR-135448, Pratt and Whitney, East Hartford, CT, 1978.

[44] G. Sallee, Performance deterioration based on in-service engine data: JT9D jet engine diagnostics program, Report No.: NASA-CR-159525, Pratt and Whitney, East Hartford, CT, 1979.

[45] S. Chatterjee, J. Litt, Online model parameter estimation of jet engine degradation for autonomous propulsion control, AIAA Guidance, Navigation, and Control Conference and Exhibit, 2003, pp. 5425.

[46] F. Giri, E.-W. Bai, Block-oriented nonlinear system identification, Springer2010.

[47] L.A. Aguirre, M.C.S. Coelho, M.V. Correa, On the interpretation and practice of dynamical differences between Hammerstein and Wiener models, IEE Proceedings - Control Theory and Applications, 152 (2005) 349-356.

[48] E.W. Otto, B.L. Taylor III, Dynamics of a turbojet engine considered as a quasi-static system, Report No.: NACA-TR-1011, Lewis Flight Propulsion Lab, National Advisory Committee for Aeronautics, Cleveland, Ohio, 1951.

[49] E. Mohammadi, M. Montazeri-Gh, P. Khalaf, Metaheuristic Design and Optimization of Fuzzy-Based Gas Turbine Engine Fuel Controller Using Hybrid Invasive Weed Optimization/Particle Swarm Optimization Algorithm, J. Eng. Gas Turbines Power, 136 (2013).

[50] S. Jafari, P. Khalaf, M. Montazeri-Gh, Multi-objective meta heuristic optimization algorithm with multi criteria decision making strategy for aero-engine controller design, International Journal of Aerospace Sciences, 3 (2014) 617.

[51] C. Evans, Testing and modelling aircraft gas turbines: an introduction and overview, IET Conference Proceedings, Institution of Engineering and Technology, 1998, pp. 1361-1366.

[52] R. Poli, J. Kennedy, T. Blackwell, Particle swarm optimization, Swarm Intell., 1 (2007) 33-57.

[53] S. Sampath, R. Singh, An Integrated Fault Diagnostics Model Using Genetic Algorithm and Neural Networks, J. Eng. Gas Turbines Power, 128 (2006) 49-56.

[54] S. Sampath, Y.G. Li, S.O.T. Ogaji, R. Singh, Fault Diagnosis of a Two Spool Turbo-Fan Engine Using Transient Data: A Genetic Algorithm Approach, ASME Turbo Expo 2003, collocated with the 2003 International Joint Power Generation Conference, 2003, pp. 351-359.

[55] T. Kobayashi, D.L. Simon, Evaluation of an Enhanced Bank of Kalman Filters for In-Flight Aircraft Engine Sensor Fault Diagnostics, J. Eng. Gas Turbines Power, 127 (2005) 497-504.

[56] R. Ganguli, Gas Turbine Diagnostics: Signal Processing and Fault Isolation, Taylor \& Francis2012. 
$2020-11-21$

\title{
Hybrid Wiener model: an on-board
} approach using post-flight data for gas turbine aero-engines modelling

\author{
Wei, Zhiyuan
}

Elsevier

Wei Z, Jafari S, Zhang S, Nikolaidis T. (2020) Hybrid Wiener model: an on-board approach using post-flight data for gas turbine aero-engines modelling. Applied Thermal Engineering, Volume 184, February 2021, Article number 116350 https://doi.org/10.1016/j.applthermaleng.2020.116350 Downloaded from Cranfield Library Services E-Repository 